\title{
Tropical and Subtropical Meridional Latent Heat Transports by Disturbances to the Zonal Mean and Their Role in the General Circulation
}

\author{
TIFFANY A. SHAW \\ Department of Earth and Environmental Sciences, and Department of Applied Physics and Applied Mathematics, \\ Columbia University, New York, New York \\ OLIVIER PAULUIS \\ Center for Atmosphere Ocean Science, Courant Institute, New York University, New York, New York
}

(Manuscript received 8 September 2011, in final form 13 December 2011)

\begin{abstract}
The spectrum of meridional latent heat transport in the tropics and subtropics by disturbances to the zonal mean during all seasons is analyzed. The transport is divided into stationary and transient planetary- and subplanetary-scale eddy contributions.

The stationary transport is largest in the subtropical lower troposphere and dominates the overall transport during summer. It is of planetary scale and the zonal scale of the transport corresponds to the number of subtropical anticyclones. The transient transport is large from the surface up to the midtroposphere and from the tropics to subpolar latitudes. It is dominated by the subplanetary-scale contribution during all seasons. Westward (eastward)- propagating waves dominate the transport in the tropics (subtropics and midlatitudes). The analysis reveals that, while the total eddy meridional latent heat transport is seamless from the deep tropics to the pole, it represents the sum of transport by distinct dynamical features.

The role of the eddy meridional latent heat transport in the moist isentropic circulation is assessed using the statistical transformed Eulerian mean formulation, which converts the eddy transports into streamfunctions. The addition of the eddy latent heat streamfunction to the Eulerian mean plus eddy sensible heat streamfunction increases the mass transport by a factor of 2-3 in the subtropics and midlatitudes. The eddy transport is found to dominate the transport across the subtropical boundary. During Northern Hemisphere summer there is virtually no circulation in the absence of eddy latent heat transport. The results highlight the important role of latent heat transport by subtropical anticyclones and tropical and baroclinic waves in the general circulation.
\end{abstract}

\section{Introduction}

The earth's incoming shortwave and outgoing longwave radiation vary relatively smoothly with latitude and consequently the meridional energy transport by the atmosphere is seamless from equator to pole (Peixoto and Oort 1992; Trenberth and Stepaniak 2003). Advection by the Eulerian mean meridional circulation dominates the total energy transport in the tropics. The poleward energy transport by the Hadley circulation is the result of the poleward transport of gravitational potential energy; both

Corresponding author address: Dr. Tiffany A. Shaw, Department of Earth and Environmental Sciences, and Department of Applied Physics and Applied Mathematics, Columbia University, P.O. Box 1000, 61 Route 9W, Palisades, NY 10964.

E-mail: tas2163@columbia.edu the sensible and latent heat transports are equatorward. While the total energy transport is seamless from equator to pole, the energy transport by the Eulerian mean circulation is not: it changes sign from poleward to equatorward at the equatorward edge of the Ferrel cell, which reflects the change of sign of the Eulerian mean circulation. In the region of the Ferrel cell, a poleward energy transport is achieved by atmospheric eddies, which transport both sensible and latent heat poleward. The importance of the eddy sensible heat transport is reflected in our understanding of the general circulation. It is well known that an equator-to-pole overturning circulation can be achieved after the Eulerian mean and eddy sensible heat transports are combined, as in the transformed Eulerian mean (TEM) (Andrews and McIntyre 1978; Andrews et al. 1987) and dry isentropic (Held and Schneider 1999) circulations. The spectral 
characteristics of the eddies contributing to the poleward sensible heat transport are well known. In midlatitudes, during all seasons except winter in the Northern Hemisphere (NH), the transport is dominated by eastwardpropagating synoptic-scale waves with zonal wavenumbers $k=4-7$ and phase speeds between 5 and $15 \mathrm{~m} \mathrm{~s}^{-1}$ (Randel and Held 1991). During NH winter, the transport in mid-to-high latitudes also involves stationary planetary-scale waves with $k=1-3$ (Randel and Held 1991). The stationary wave transport is attributed to the well-known northern winter stationary waves (Held et al. 2002). Overall, the eddy sensible heat transport is very weak in the tropics and subtropics where the temperature gradients are small.

In contrast to the eddy meridional sensible heat transport, the eddy meridional latent heat (or equivalently specific humidity) transport and its role in the general circulation have received comparatively less attention. It is known that the eddy meridional latent heat transport is poleward from the deep tropics to subpolar latitudes (Peixoto and Oort 1992; Pierrehumbert and Yang 1993; Pierrehumbert 1998; Schneider et al. 2006). In midlatitudes, the eddy meridional latent heat transport is dominated by transient baroclinic waves. The transport is also large in the tropics and subtropics where there exist various dynamical features, namely subtropical anticyclones (Rodwell and Hoskins 2001; Nigam and Chan 2009) and tropical (Kiladis et al. 2009) and baroclinic waves. However, the spectral characteristics of the eddies (e.g., the wavenumbers and phase speeds) responsible for the latent heat transport in the tropics, subtropics, and midlatitudes have not been studied in detail. As for the sensible heat transport, the Eulerian mean circulation dominates the total latent heat transport in the deep tropics; however, there is considerable overlap between the Eulerian mean and eddy latent heat transports, particularly in the subtropics. This is reflected in the moist isentropic circulation. Pauluis et al. $(2008,2010)$ found that the mass transport by the moist isentropic circulation was larger than the dry circulation in the subtropics and midlatitudes. However, the fraction of the mass transport by the moist isentropic circulation that is attributable to meridional eddy latent heat transport is unknown. A particular challenge for understanding the role of eddy meridional latent heat transport in the general circulation is that the TEM formulation cannot be directly applied to a scalar that includes both sensible and latent heat transports (e.g., the equivalent potential temperature) because it exhibits a midtropospheric minimum, and thus a vanishing vertical derivative, in a region where the meridional transport is large. Recently, Pauluis et al. (2011) derived a new statistical TEM (STEM) formulation that can be applied to the equivalent potential temperature and therefore to the moist isentropic circulation.

Here we investigate the spectral characteristics of the eddy meridional latent heat transport in order to understand what aspects of the general circulation are responsible for it and how it complements the well-known sensible heat transport. In particular, we address whether the poleward eddy latent heat transport is seamless from equator to pole for a given spectral window and the role the transport plays in the moist isentropic circulation. Section 2 describes the data and analysis methods used in this study. Section 3 discusses the spectrum of meridional latent heat transport and its decomposition into stationary and transient planetary- and subplanetary-scale zonal wavenumber contributions. In section 4 , the STEM formulation is used to understand the role of eddy latent heat transport in the moist isentropic circulation. The results are summarized and discussed in section 5 .

\section{Data and analysis methods}

The data used in this study are the daily threedimensional meridional wind, specific humidity, and temperature from the interim European Centre for Medium-Range Weather Forecasts (ECMWF) Re-Analysis (ERA-Interim) dataset covering the period from 1 January 1979 to 31 December 2010 (Dee et al. 2011). ${ }^{1}$ The data are provided on pressure levels with a horizontal resolution of $1.5^{\circ}$. In the analysis that follows, all of the ERA-Interim results were found to be in qualitative agreement with the results from the National Centers for Environmental Prediction (NCEP-1 and NCEP-2).

Here eddies are defined as deviations from the daily zonal mean. This definition represents a starting point for separating the Eulerian mean circulation from the eddyinduced circulation as is conventional in the TEM formulation (Andrews and McIntyre 1978; Andrews et al. 1987). The meridional latent heat transport is calculated by multiplying the meridional specific humidity transport by $L_{v} / c_{p}$, where $L_{v}$ is the latent heat of vaporization and $c_{p}$ is the specific heat at constant pressure, which allows for a direct comparison with the sensible heat transport (both have units of $\mathrm{K} \mathrm{m} \mathrm{s}^{-1}$ ). The eddy latent heat transport is divided into stationary and transient contributions using

\footnotetext{
${ }^{1}$ Similar calculations using 6-hourly data produced eddy meridional latent heat fluxes that were on the order of $20 \%$ larger than those calculated with daily data, in agreement with previous calculations (A. Donohoe 2011, personal communication). However, the enhanced eddy latent heat transport did not lead to large differences in the moist isentropic circulation calculated in section 4 because of correspondingly large increases in the eddy variance [see (1)].
} 

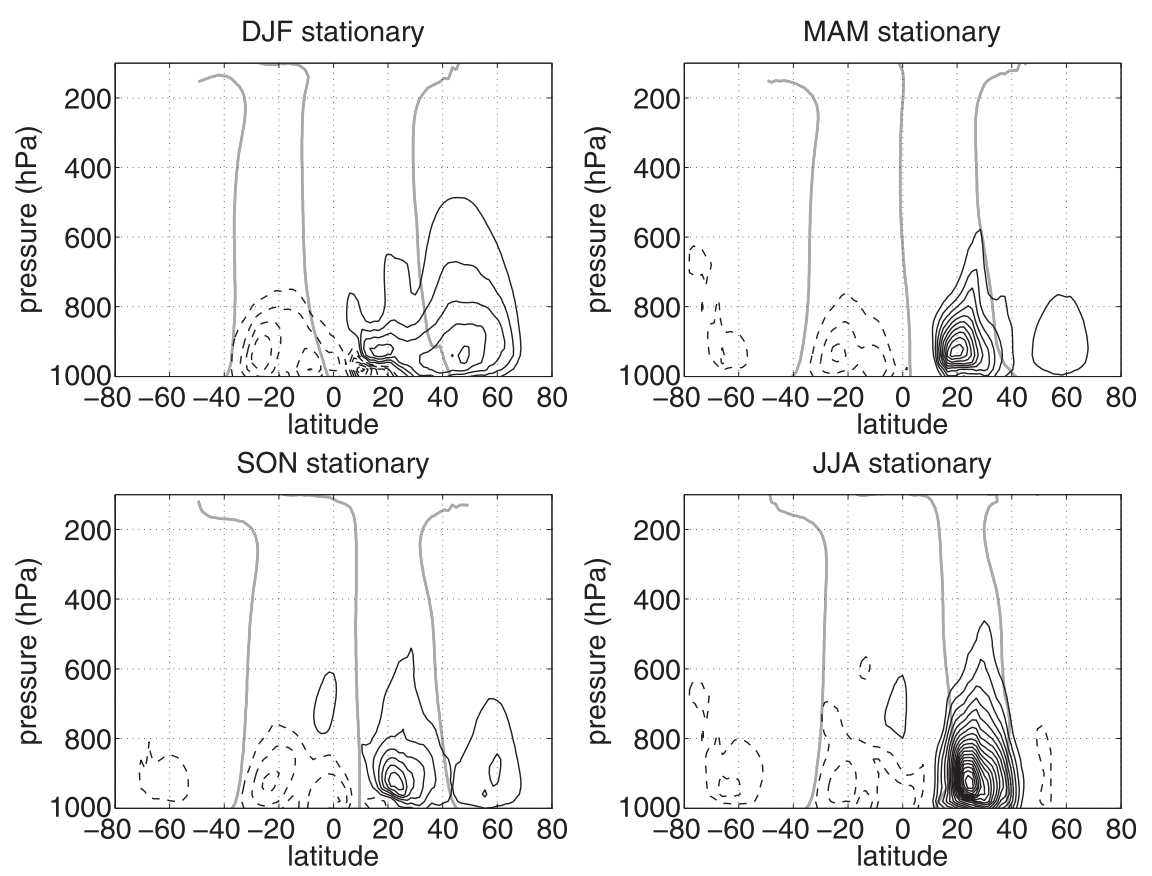

FIG. 1. Zonal-mean cross section of stationary planetary-scale $(k=1-3)$ eddy meridional latent heat transport during (top left) DJF, (top right) MAM, (bottom right) JJA, and (bottom left) SON. Contour interval is $1 \mathrm{~K} \mathrm{~m} \mathrm{~s}^{-1}$. The thick gray lines show the zero contour of the Eulerian mean streamfunction.

a monthly time average [see Eq. (4.7) in Peixoto and Oort 1992 ] and then further subdivided into zonal wavenumber $k$ contributions associated with planetary $k=1-3$ and subplanetary $k \geq 4$ scale waves. The analysis focuses on eddy meridional latent heat transport during individual seasons: December-February (DJF), March-May (MAM), June-August (JJA), and September-November (SON). The eddy characteristics of the transient transport are analyzed using the phase speed cospectrum introduced by Hayashi (1971). The cospectral analysis is performed on 120-day time series for the respective seasons as in Randel and Held (1991). For each 120-day period and for all latitudes a wavenumber-frequency spectrum is calculated and converted into a phase speed spectrum. The phase speed spectra for all years are then averaged.

\section{Spectrum of eddy meridional latent heat transport}

The seasonal evolution of the zonal-mean planetaryand subplanetary-scale stationary eddy meridional latent heat transports are shown in Figs. 1 and 2, respectively. In all figures the seasonal evolution from DJF to SON is presented in a clockwise direction beginning with the top left panel. The zero contours of the Eulerian mean streamfunction between $50^{\circ} \mathrm{S}$ and $50^{\circ} \mathrm{N}$ are denoted by gray lines. For comparison, recall that the Eulerian mean circulation transports latent heat equatorward in the region of the Hadley cell and poleward in the region of the Ferrel cell. The stationary eddy latent heat transport is predominantly poleward in both hemispheres during all seasons. The transport is large below $600 \mathrm{hPa}$ and occurs mainly in the vicinity of the Hadley circulation with the exception of DJF in the NH. The planetary-scale transport dominates in the $\mathrm{NH}$ and maximizes during JJA. The NH transport during DJF extends from the subtropics to subpolar latitudes and maximizes at $50^{\circ} \mathrm{N}$. The extension into the subpolar region is associated with the well-known northern winter stationary waves (Held et al. 2002), which have zonal wavenumbers $k=1-3$ (Randel and Held 1991). The planetary-scale transport in the Southern Hemisphere $(\mathrm{SH})$ is weaker than the corresponding NH transport. The subplanetary-scale transport dominates in the $\mathrm{SH}$ and is particularly large during DJF and SON (SH summer and spring). The largest transport occurs in the vicinity of the Hadley circulation. The dominant zonal length scales of the stationary transport in the subtropics of both hemispheres correspond to the number of subtropical anticyclones in the respective hemispheres [two in NH summer and three to four in $\mathrm{SH}$ summer; see Fig. 1 of Rodwell and Hoskins (2001)], which is related to the continental configuration. Note that the stationary transport by the subtropical anticyclones is present during all seasons but is significantly 

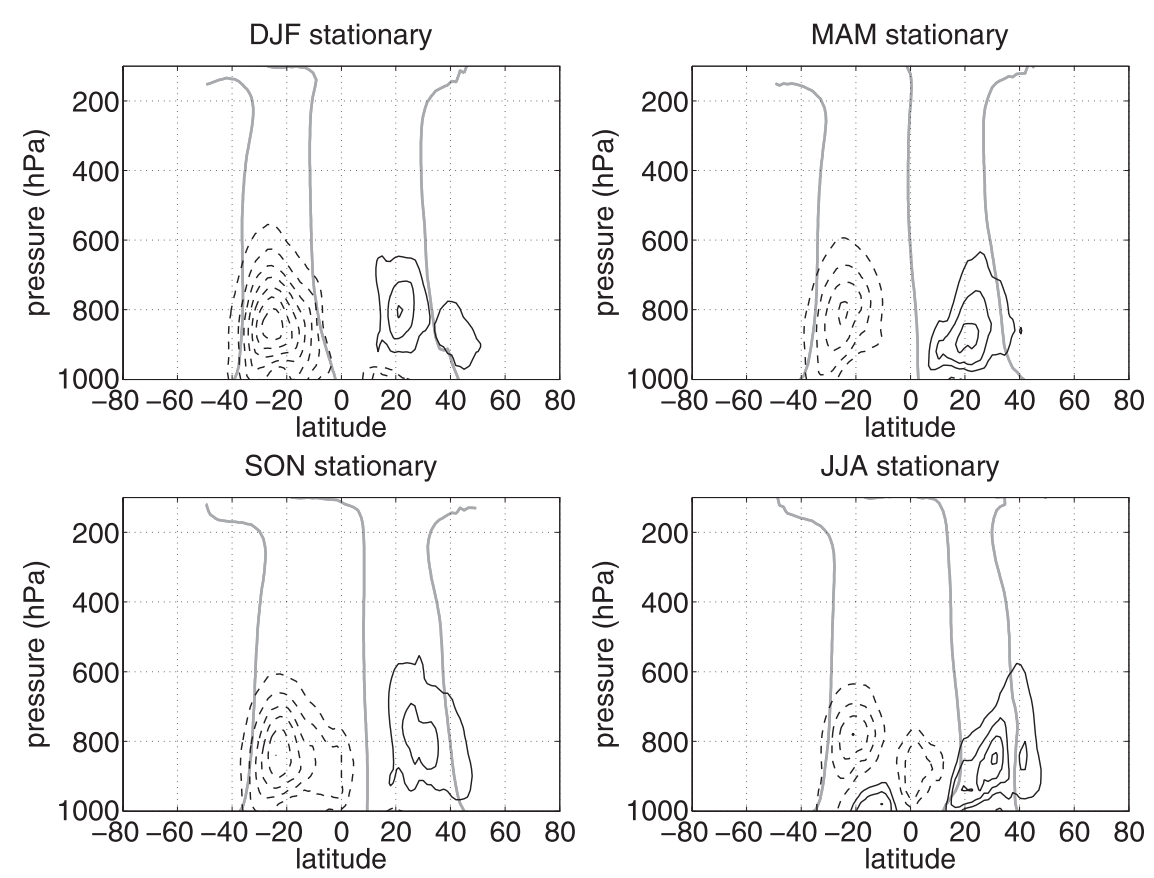

FIG. 2. As in Fig. 1, but for stationary subplanetary-scale $(k \geq 4)$ eddy meridional latent heat transport.

enhanced during summer in the presence of the monsoons, which is consistent with Nigam and Chan (2009). The subtropical anticyclones and the monsoons form the summer subtropical circulation, as discussed by Rodwell and Hoskins (2001).

Figure 3 shows the corresponding stationary planetaryscale eddy sensible heat transport during all seasons. The planetary-scale sensible heat transport is strikingly different from the latent heat transport (cf. Figs. 1 and 3). It is weak in the subtropics and extends much higher in the atmosphere. Furthermore, during JJA the sensible and latent transports have the opposite sign in the vicinity of the NH Hadley circulation; sensible heat is transported toward the equator (cf. the bottom right panels of Figs. 1 and 3). The subplanetary-scale sensible heat transport is similar to its latent heat counterpart; it is poleward and confined below $600 \mathrm{hPa}$ (not shown).

The seasonal evolution of the planetary- and subplanetary-scale transient latent heat transports are shown in Figs. 4 and 5, respectively. The transient planetaryscale transport is very weak during all seasons. It occurs mainly in polar latitudes from $60^{\circ}$ to $80^{\circ}$. Overall, the transient eddy meridional latent heat transport is dominated by subplanetary-scale waves and is poleward during all seasons. Unlike the stationary transport, which is mostly confined below $600 \mathrm{hPa}$ and to the tropics and subtropics, the transient transport extends up to $400 \mathrm{hPa}$ and from the deep tropics to subpolar latitudes. The transient transport extends across the region of the Hadley and Ferrel cells. It reaches an extremum near the poleward edge of the Hadley cell. The SH transport dominates over the $\mathrm{NH}$ transport and the $\mathrm{SH}$ extremum is located near $40^{\circ} \mathrm{S}$ at $850 \mathrm{hPa}$ during all seasons. In contrast, the $\mathrm{NH}$ extremum moves throughout the seasonal cycle. During winter and spring it is located near $35^{\circ} \mathrm{N}$, during summer it is located at $50^{\circ} \mathrm{N}$ and the transport is very weak in the subtropics, and finally during autumn the extremum shifts back to $40^{\circ} \mathrm{N}$.

Figure 6 shows the corresponding subplanetary-scale transient eddy sensible heat transport during all seasons. The sensible heat transport extends much higher in the atmosphere than the corresponding latent heat transport. The difference in the vertical extent of the sensible and latent heat transports is the result of the different scale heights of potential temperature versus specific humidity. The transport below $700 \mathrm{hPa}$ is very weak in the deep tropics in the winter and summer hemispheres, respectively. Above $700 \mathrm{hPa}$ the transport is weak in the region of the Hadley cell and the transport is large and poleward in the region of the Ferrel cell. During DJF the transport in the deep tropics at $500 \mathrm{hPa}$ is equatorward, which is opposite to the latent heat transport. Overall, the sensible heat transport extrema are approximately $5^{\circ}$ poleward of the latent heat extrema with the exception of summer in the NH. As for the latent heat transport, the subplanetary-scale transient eddy sensible heat transport is poleward during all seasons but is much weaker than the planetary-scale transport (not shown). 

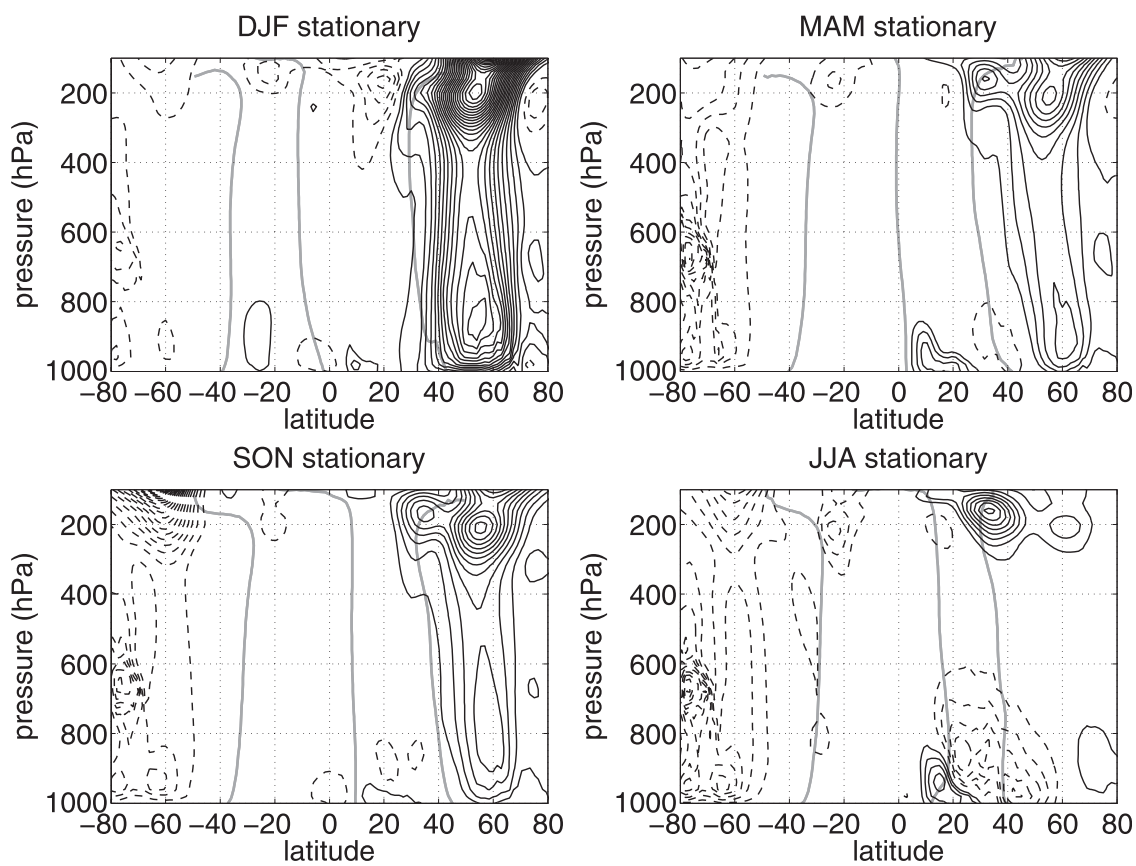

FIG. 3. As in Fig. 1, but for eddy sensible heat transport.

The extension of the transient latent heat transport across the subtropics and into the deep tropics raises questions about the characteristics of the eddies involved, particularly their phase speeds. The zonal-mean zonal wind changes sign from eastward to westward in the subtropics. Furthermore, the subtropics are considered as a transition region between tropical wave dynamics and midlatitude baroclinic eddy dynamics. Both
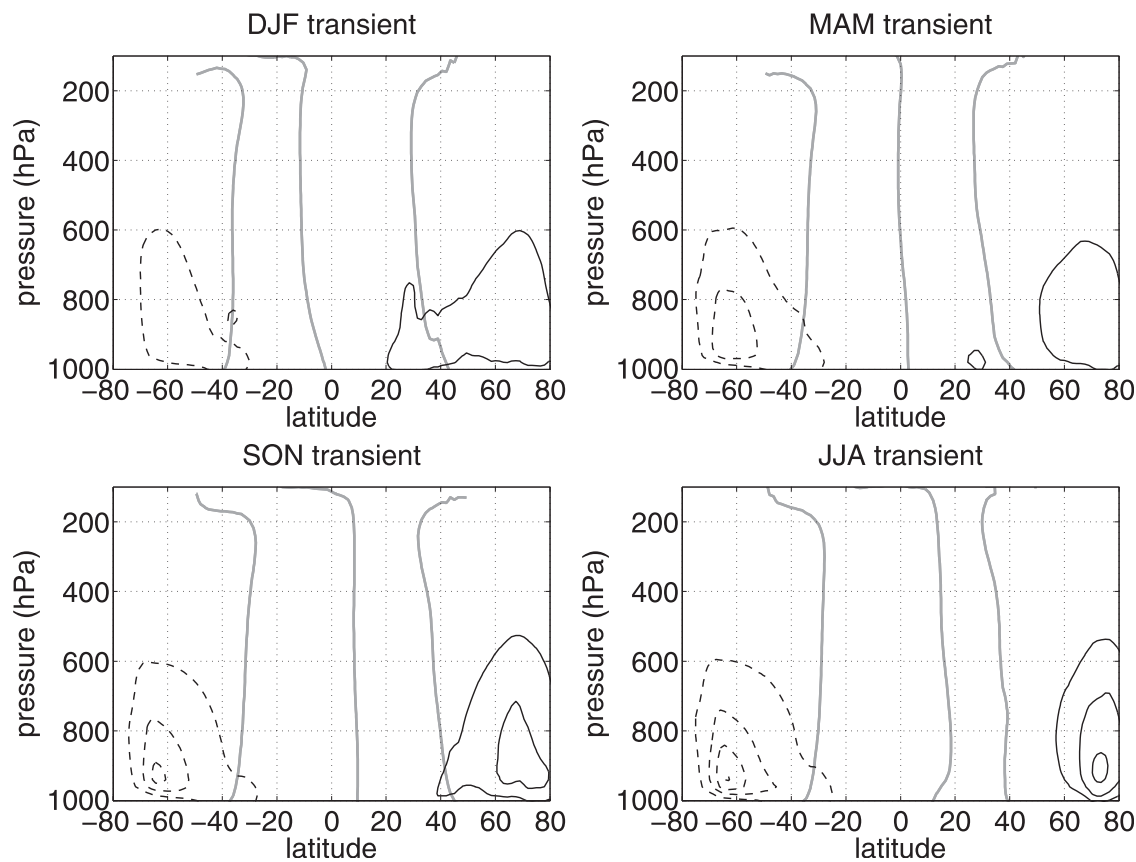

FIG. 4. Zonal-mean cross section of transient planetary-scale $(k=1-3)$ eddy meridional latent heat transport during (top left) DJF, (top right) MAM, (bottom right) JJA, and (bottom left) SON. Contour interval is $1 \mathrm{~K} \mathrm{~m} \mathrm{~s}^{-1}$. The thick gray lines show the zero contour of the Eulerian mean streamfunction. 

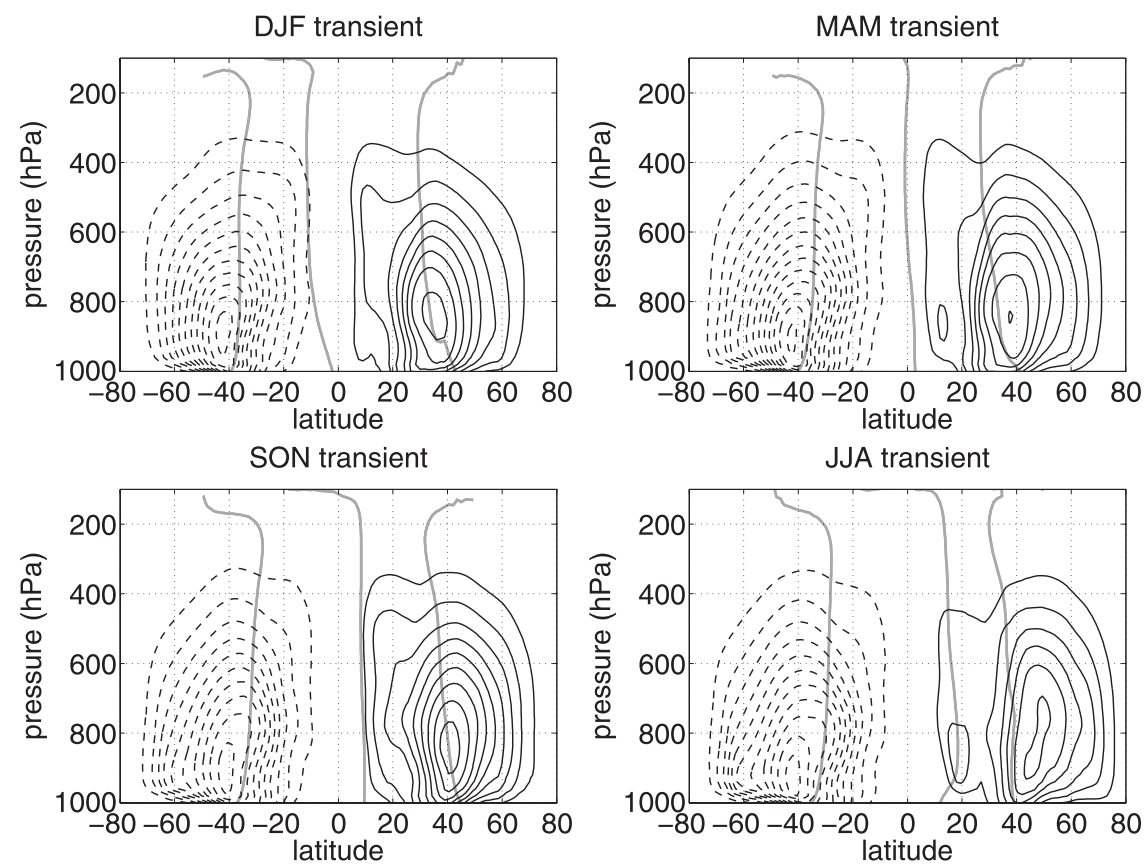

FIG. 5. As in Fig. 4, but for transient subplanetary-scale $(k \geq 4)$ eddy meridional latent heat transport.

types of waves likely play a role in the subtropics. The wavenumber-frequency characteristics of the transient eddies in the tropics and subtropics can be assessed using the cospectral analysis of Hayashi (1971). Randel and Held (1991) applied the cospectral analysis to the sensible heat transport in the lower and midtroposphere
(700 and $500 \mathrm{hPa}$, respectively). They showed that the transient sensible heat transport at $700 \mathrm{hPa}$ was maximum in the region of the midlatitude storm tracks for subplanetary-scale $(k=4-7)$ waves moving eastward with phase speeds of $c=5-15 \mathrm{~m} \mathrm{~s}^{-1}$ (see their Figs. 2 and 5). They noted that higher wavenumber disturbances
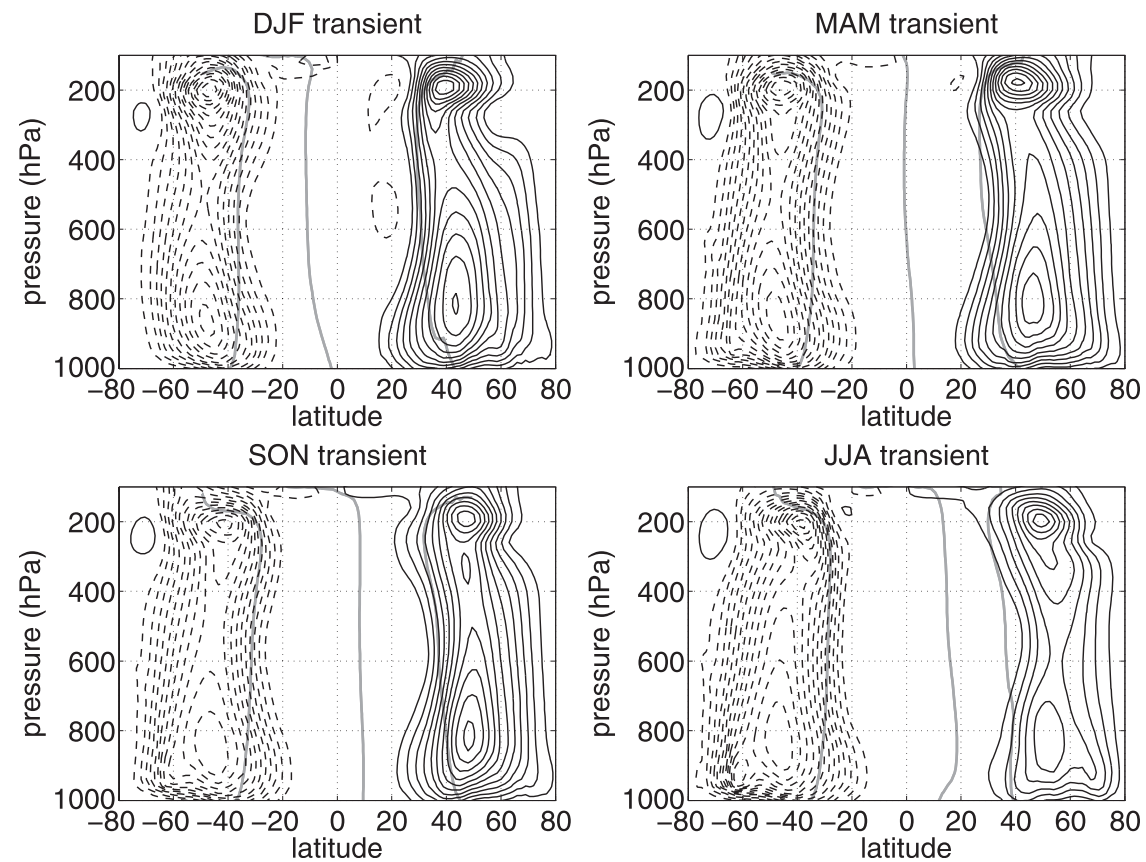

FIG. 6. As in Fig. 5, but for eddy sensible heat transport. 

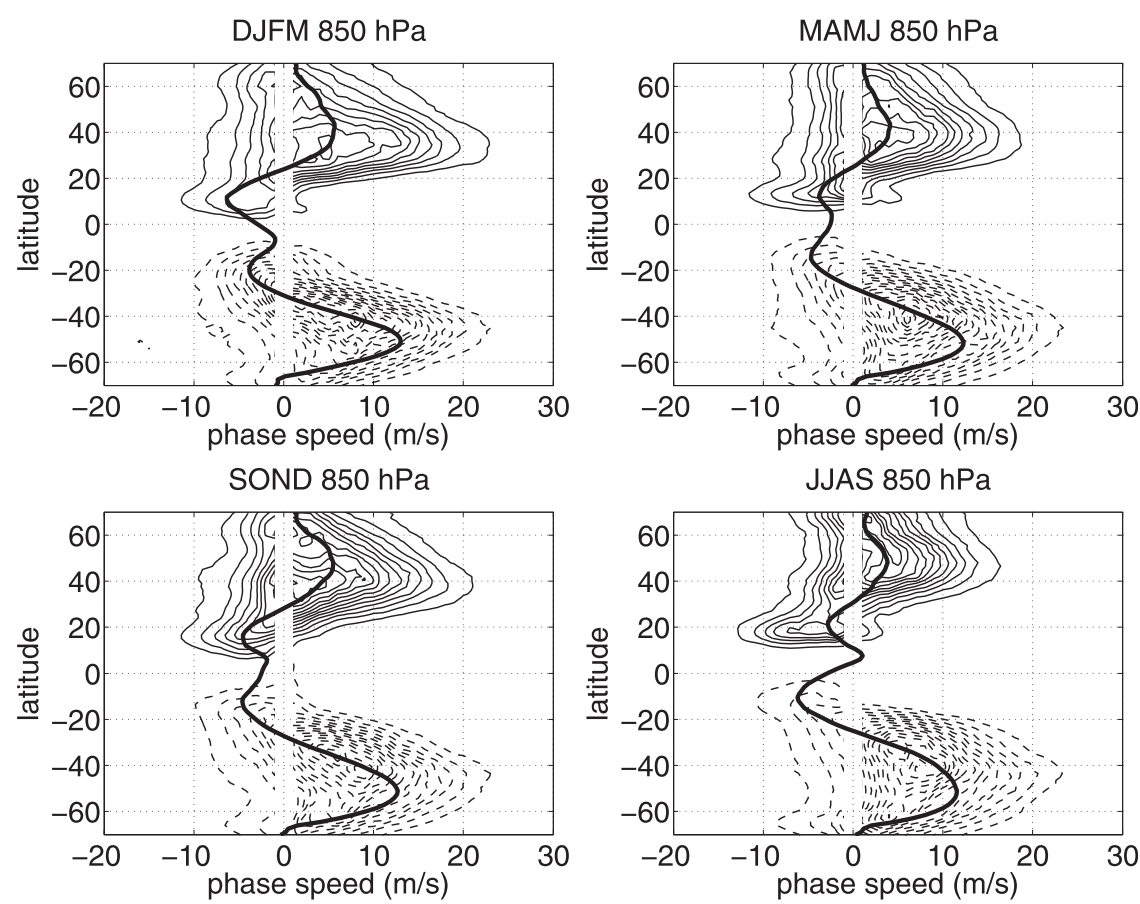

FIG. 7. Transient eddy meridional latent heat flux vs latitude and phase speed during (top left) DJF, (top right) MAM, (bottom right) JJA, and (bottom left) SON at $850 \mathrm{hPa}$. Contour interval is $0.05 \mathrm{~K} \mathrm{~m} \mathrm{~s}^{-1} \Delta c^{-1}$. The thick black line shows the time and zonally averaged zonal wind at $850 \mathrm{hPa}$.

move with successively faster eastward phase speeds in accordance with Rossby wave dynamics. The latitudinal extent of the sensible heat transport changed seasonally; the winter extrema were $10^{\circ}$ equatorward of summer extrema. The eddy sensible heat transport was found to be very weak in the subtropics, which was also seen in Fig. 6.

Figure 7 shows the eddy meridional latent heat transport phase speed cospectra as a function of latitude at $850 \mathrm{hPa}$ (roughly where the transport reaches its extrema in height) from December-March (DJFM) to SeptemberDecember (SOND), respectively. In all figures the seasonal evolution from DJFM to SOND is presented in a clockwise direction beginning with the top left panel. In all panels the thick black line shows the zonal-mean zonal wind. In both hemispheres and during all seasons the transport is spread from the deep tropics to subpolar latitudes as seen in the zonal-mean cross sections (see Fig. 5). During each season there are clear phase speed extrema that are suggestive of wavelike transport. The extrema are aligned with the zonal-mean zonal wind. The transient transport in the $\mathrm{SH}$ dominates over the $\mathrm{NH}$ transport with the exception of SOND when they are of equal magnitude. In the subtropics the transient transport is dominated by eastward-propagating waves with phase speeds $c=5-10 \mathrm{~m} \mathrm{~s}^{-1}$ during all seasons. The waves have zonal wavenumbers $k=5-8$ (not shown). While the transport by eastward-propagating waves dominates in the subtropics, there is also significant power for westward phase speeds in the deep tropics during all seasons. The westward phase speeds range from $c=-2$ to $-7 \mathrm{~m} \mathrm{~s}^{-1}$ and in most cases the waves are intrinsically westward; the westward phase speed cannot be accounted for by advection due to the zonal-mean zonal wind alone.

The eddy meridional latent heat transport by eastward(blue) and westward- (green) propagating and by stationary (red) waves at $850 \mathrm{hPa}$ during all seasons is shown in Fig. 8. The black line shows the total seasonal eddy transport, which is poleward and seamless from equator to pole during all seasons. The dominant contributions at this level are from transient eastward-propagating and stationary waves. The eastward wave transport peaks at the edge of the subtropics with the exception of JuneSeptember (JJAS) in the NH where it peaks at $50^{\circ} \mathrm{N}$. The eastward-propagating waves produce a divergence of latent heat from the subtropics and a convergence of latent heat in the mid- and subpolar latitudes. In addition there is stationary transport on the equatorward and poleward flanks of the eastward wave transport during DJFM in the NH. The stationary waves are planetary scale (see Fig. 1). During spring and summer in both hemispheres, there is large stationary wave transport in the subtropics with eastward wave transport on its poleward flank. The $\mathrm{NH}$ 

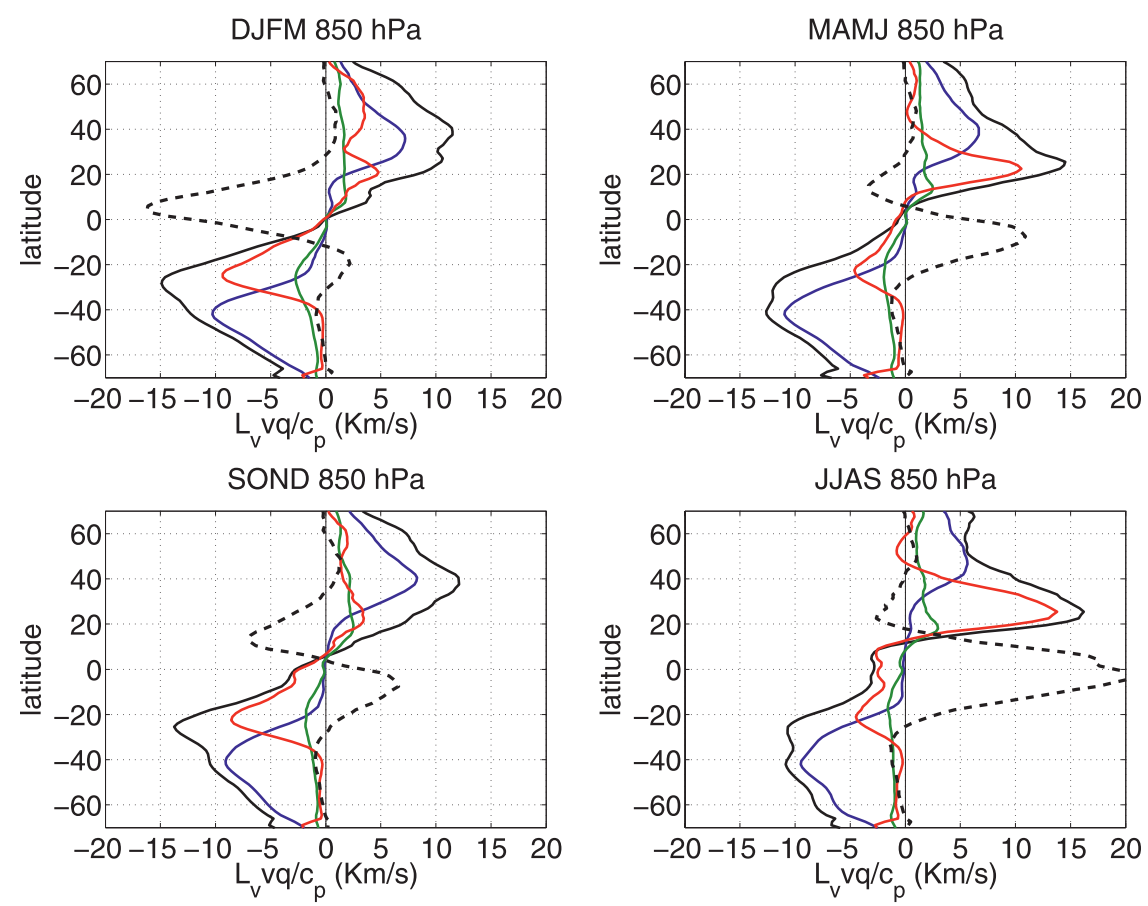

FIG. 8. Meridional eddy latent heat transport by eastward (blue), westward (green), and stationary (red) waves at $850 \mathrm{hPa}$ during (top left) DJF, (top right) MAM, (bottom right) JJA, and (bottom left) SON. The total eddy transport is shown in the black line. The dashed line shows the corresponding Eulerian mean transport, which has been divided by 2.5 so that it can be displayed for the chosen range of heat transport.

(SH) stationary wave transport is dominated by waves with zonal wavenumbers $k=1-2(k=3-4)$. The stationary waves produce a divergence of latent heat from the tropics and a convergence in the subtropics. When taken together the stationary and eastward-propagating waves produce a divergence of latent heat from the tropics and subtropics and a convergence in mid-to-high latitudes.

The total eddy meridional latent heat transport at $850 \mathrm{hPa}$ can be compared to the transport by the Eulerian mean circulation (dashed line in Fig. 8). Note that the Eulerian mean transport has been divided by 2.5 so that it can be displayed for the chosen range of heat transport. The Eulerian mean transport dominates in the deep tropics during all seasons. It involves a divergence from the tropics of the winter hemisphere and a convergence in the tropics of the summer hemisphere. During the equinoxes, the mean transport produces a divergence from the subtropics and a convergence in the tropics. The latitude of zero eddy meridional latent heat transport corresponds to the latitude where the latent heat transport by the Eulerian mean circulation is zero during MAMJ and SOND. However, during DJFM and JJAS there is a $5^{\circ}$ to $10^{\circ}$ difference between the latitudes of zero mean and eddy transport. Overall, the eddy transport dominates the total transport poleward of approximately $20^{\circ}$.
Figures 9 and 10 show the longitude-latitude cross section at $850 \mathrm{hPa}$ of the stationary and transient eddy meridional latent heat transports, respectively. The stationary transport at $850 \mathrm{hPa}$ shows features of the summer subtropical anticyclones, which reside around $30^{\circ}$ over the Pacific and Atlantic Oceans, and the clockwise gyre at the equator over the Indian Ocean. In particular, the large poleward transport on the western boundary of North and South America, Africa, and Australia occurs within the equatorward branch of the anticyclones, suggesting the transport of dry air. The poleward transport on the eastern side of the continents occurs within the poleward branch of the anticyclones, localized in some places as poleward flowing low-level jets (e.g., the Great Plains jet in North America and the Pampas jet in South America) that transport specific humidity poleward into the monsoon region. Over the Indian Ocean, there are two clockwise gyres at $50^{\circ}$ and $90^{\circ} \mathrm{E}$ centered at the equator. The transport over East Africa is associated with the northward branch of the clockwise gyre centered at $50^{\circ} \mathrm{E}$. The meridional eddy sensible heat transport in this region has the opposite sign to the latent heat transport, which was seen in the zonal mean (see Figs. 1 and 3, bottom right). In the $\mathrm{SH}$ there are clear signatures of the South Pacific and South Atlantic convergence zones. 

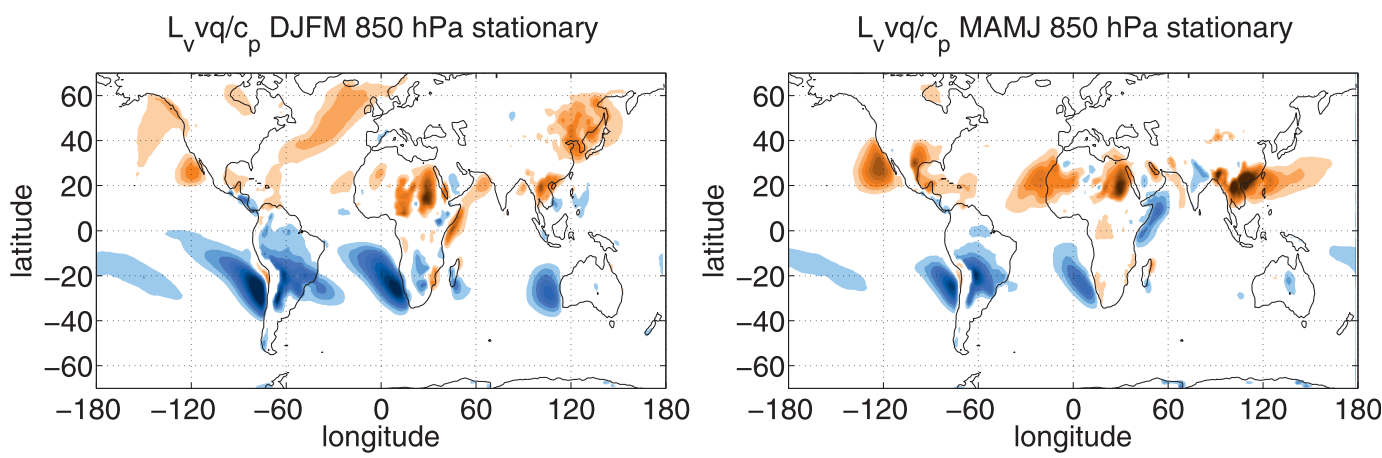

$\mathrm{L}_{\mathrm{v}} \mathrm{vq} / \mathrm{c}_{\mathrm{p}}$ SOND $850 \mathrm{hPa}$ stationary

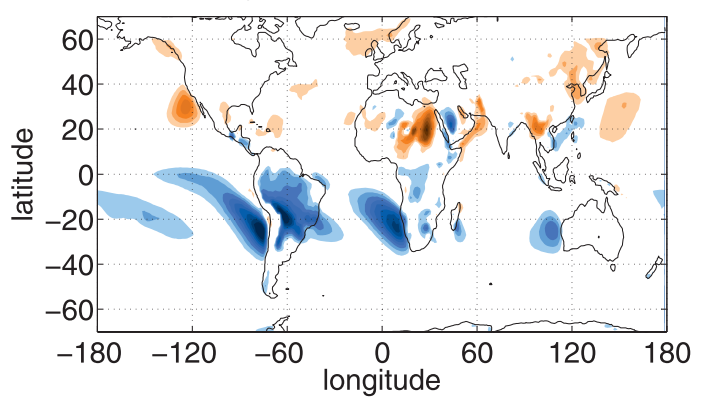

$\mathrm{L}_{\mathrm{v}} \mathrm{vq} / \mathrm{c}_{\mathrm{p}} \mathrm{JJAS} 850 \mathrm{hPa}$ stationary

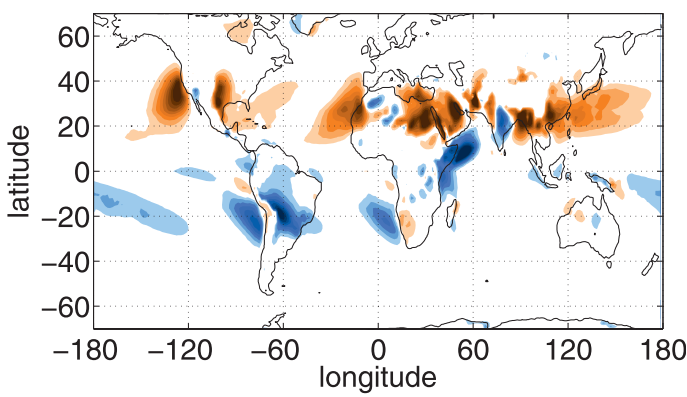

FIG. 9. Stationary eddy meridional latent heat transport at $850 \mathrm{hPa}$ for: (top left) DJFM and (top right) MAMJ; (bottom left) SOND and (bottom right) JJAS. Contour interval is $5 \mathrm{~K} \mathrm{~m} \mathrm{~s}^{-1}$.

Note that the abovementioned features of the stationary transport occur during all seasons but are strongest during the summer when the monsoons amplify the transport. Overall, the transient transport at $850 \mathrm{hPa}$ is much broader in latitude (Fig. 10). It extends from the subtropics, in the vicinity of the poleward branch of the subtropical anticyclones, across the ocean basin to the pole. The transient transport peaks where other metrics
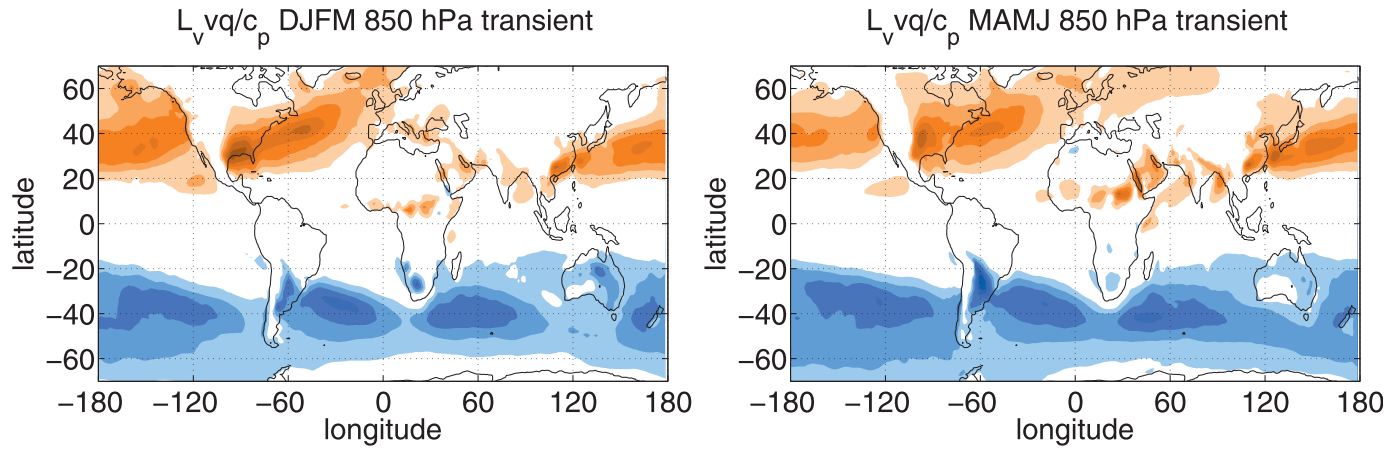

$\mathrm{L}_{\mathrm{v}} \mathrm{vq} / \mathrm{c}_{\mathrm{p}}$ SOND $850 \mathrm{hPa}$ transient

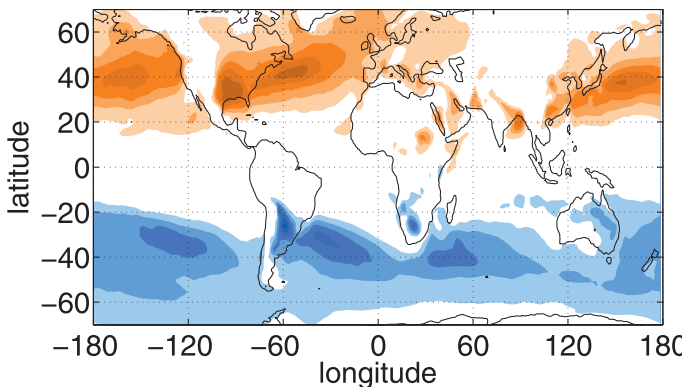

$\mathrm{L}_{\mathrm{v}} \mathrm{vq} / \mathrm{c}_{\mathrm{p}}$ JJAS $850 \mathrm{hPa}$ transient

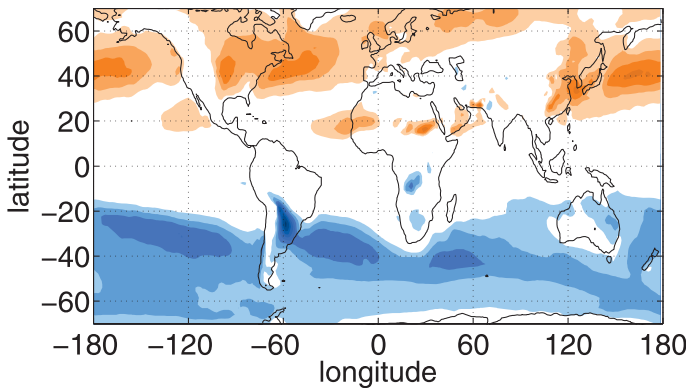

FIG. 10. As in Fig. 9, but for the transient transport. 

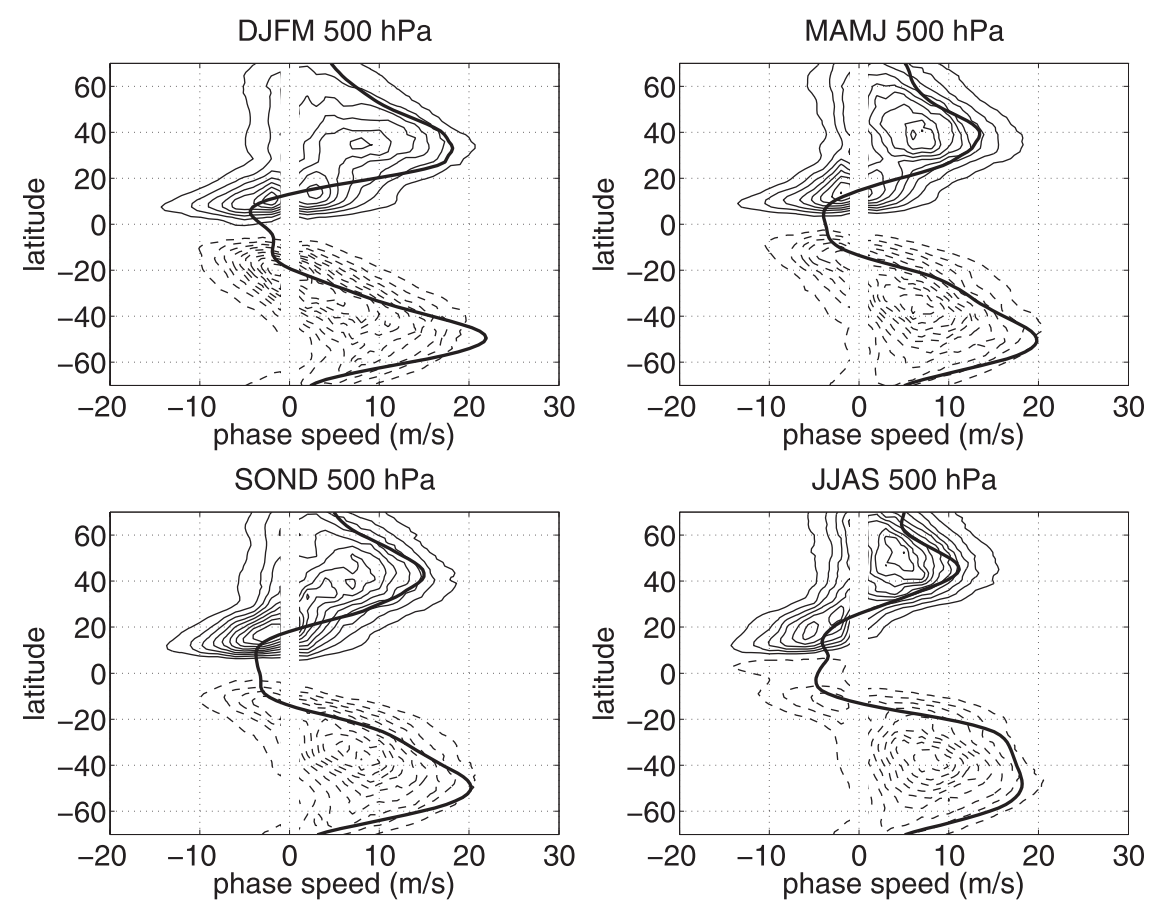

FIG. 11. As in Fig. 7, but at $500 \mathrm{hPa}$. Contour interval is $0.025 \mathrm{~K} \mathrm{~m} \mathrm{~s}^{-1} \Delta c^{-1}$.

of the storm track peak (e.g., the transient eddy kinetic energy; Chang 1999).

Figure 11 shows the eddy meridional latent heat transport phase speed cospectra as a function of latitude in the midtroposphere $(500 \mathrm{hPa})$ from DJFM to SOND, respectively. Overall, the transport at this level is weaker than that in the lower troposphere, which was also seen in the zonal-mean cross sections. The spectral power is clearly shifted into the deep tropics where westward-propagating waves with phase speeds from $c=-2$ to $-5 \mathrm{~m} \mathrm{~s}^{-1}$ and zonal wavenumbers from $k=3-6$ dominate. In the subtropics, the transient transport is dominated by eastwardpropagating waves with phase speeds $c=5-10 \mathrm{~m} \mathrm{~s}^{-1}$ and wavenumbers similar to those at $850 \mathrm{hPa}$.

The eddy meridional latent heat transport by eastward(blue) and westward- (green) propagating and stationary (red) waves at $500 \mathrm{hPa}$ during all seasons is shown in Fig. 12. The black line shows the total seasonal eddy transport. As in the lower troposphere, the total eddy transport is seamless from equator to pole; however, the dynamical contributions to the transport are different. Westward wave transport dominates in the deep tropics and is associated with a divergence of latent heat from the deep tropics and a convergence at the edge of the tropics. Eastward wave transport dominates in the subtropics and is associated with a divergence of latent heat from the subtropics and a convergence of latent heat in the mid- and subpolar latitudes. The transport by stationary waves is weaker in the midtroposphere than it was near the surface, which corresponds with a significant weakening of the subtropical anticyclones (not shown). The latent heat transport by the Eulerian mean circulation is also very weak (not shown). The eddy transport at $500 \mathrm{hPa}$ dominates the overall transport from equator to pole.

Figure 13 shows the longitude-latitude cross section at $500 \mathrm{hPa}$ of the transient eddy meridional latent heat transport. At this level, the transient transport shows a clear connection between the poleward latent heat transport in the deep tropics and that in the subtropics and midlatitudes. In particular, there is a transport maximum in the tropical eastern Pacific that extends across North America, connecting to a second maximum over the southeastern United States, and into the North Atlantic. In the $\mathrm{SH}$, latent heat is being transported from the equatorial Pacific to the North Pacific. The stationary transport at $500 \mathrm{hPa}$ is very weak (see Figs. 1 and 2) and therefore the longitude-latitude cross sections are not shown.

Randel and Held (1991) noted a nearly one-to-one correspondence between the phase speed extrema of the meridional sensible heat transport at $700 \mathrm{hPa}$ (their Fig. 5) and the meridional transport of zonal momentum at $300 \mathrm{hPa}$ (their Fig. 6) in midlatitudes. The correspondence of the spectral peaks in the vertical was consistent with a region of wave generation in the lower troposphere and wave dissipation in the upper troposphere seen in idealized baroclinic life cycle experiments [see Fig. 3 of Edmon et al. (1980) and Fig. 3 of Held and Hoskins 

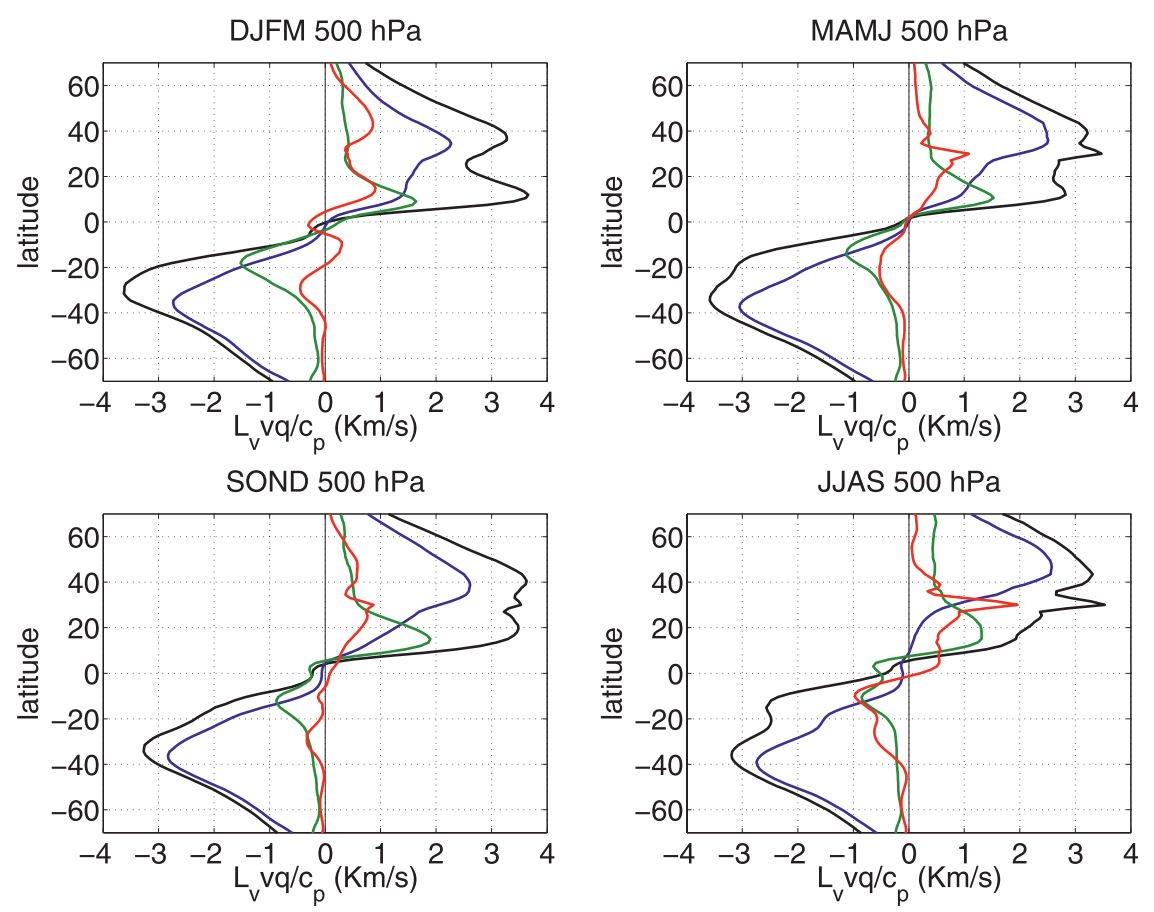

FIG. 12. Meridional eddy latent heat transport by eastward (blue), westward (green), and stationary (red) waves at $500 \mathrm{hPa}$ during (top left) DJF, (top right) MAM, (bottom right) JJA, and (bottom left) SON. The total eddy transport is shown in the black line.

(1985)]. It also reflects the fact that both the meridional transport of zonal momentum and sensible heat contribute to the Eliassen-Palm (pseudo-momentum) flux (Andrews et al. 1987). The latent heat transport phase speed extrema in the lower troposphere are in general slower than the sensible heat transport extrema (not shown). The difference in phase speed results from the difference in the zonal wavenumbers of the respective transports (e.g., the $k=5-8$ latent heat transport implies slower phase speeds than the $k=4-7$ sensible heat transport). In addition, the sensible heat transport is very weak equatorward of $20^{\circ}$ whereas the latent heat transport shows a clear transition from eastward to westward phase speeds. If latent and sensible heat were transported passively by eddies with fixed spectral characteristics, then one would expect a nearly one-to-one correspondence of their phase speed extrema (e.g., Figs. 7 and 11). The results suggest that the zonal-mean meridional gradients and sources/sinks (evaporation, precipitation, radiative cooling) play an important role in shaping the eddy characteristics. For example, the meridional gradient of the zonal-mean potential temperature is large in midlatitudes but the meridional gradient of the zonalmean specific humidity is large in the subtropics. Similarly, the strong nonconservation of specific humidity means that it is less suitable as a passive tracer than is the potential temperature. The phase speeds of the eddy meridional transport of zonal momentum at $500 \mathrm{hPa}$ in the subtropics and tropics are found to be more consistent with the eddy meridional latent heat transport than the sensible heat transport (not shown). This suggests that the eddies in the tropics and subtropics transport zonal momentum and latent heat meridionally but not sensible heat.

\section{The role of eddy meridional latent heat transport in the moist isentropic circulation}

The eddy meridional latent heat transport involves a rich spectrum of waves in the tropics and subtropics including stationary and eastward- and westward-propagating waves whose individual contribution to the poleward transport vary as a function of height. A central question is: what role do these latent heat transport contributions play in the general circulation of the atmosphere? The role of eddy meridional sensible heat transport in the general circulation is well known from the TEM residual and dry isentropic circulations. Adding the TEM eddy circulation - which is equal to the eddy meridional sensible heat transport divided by the vertical derivative of the potential temperature-to the Eulerian mean circulation results in the reversal of the Ferrel cells and an equator-to-pole overturning circulation. The circulation acts to transport air with high dry entropy poleward and low dry entropy air equatorward in such a 

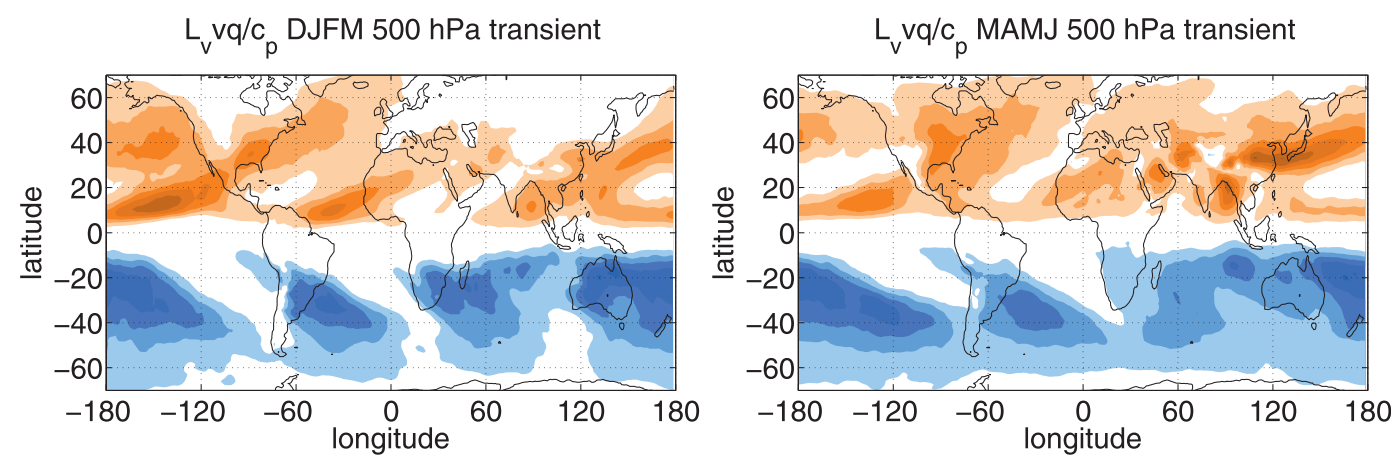

$\mathrm{L}_{\mathrm{v}} \mathrm{vq} / \mathrm{c}_{\mathrm{p}}$ SOND $500 \mathrm{hPa}$ transient
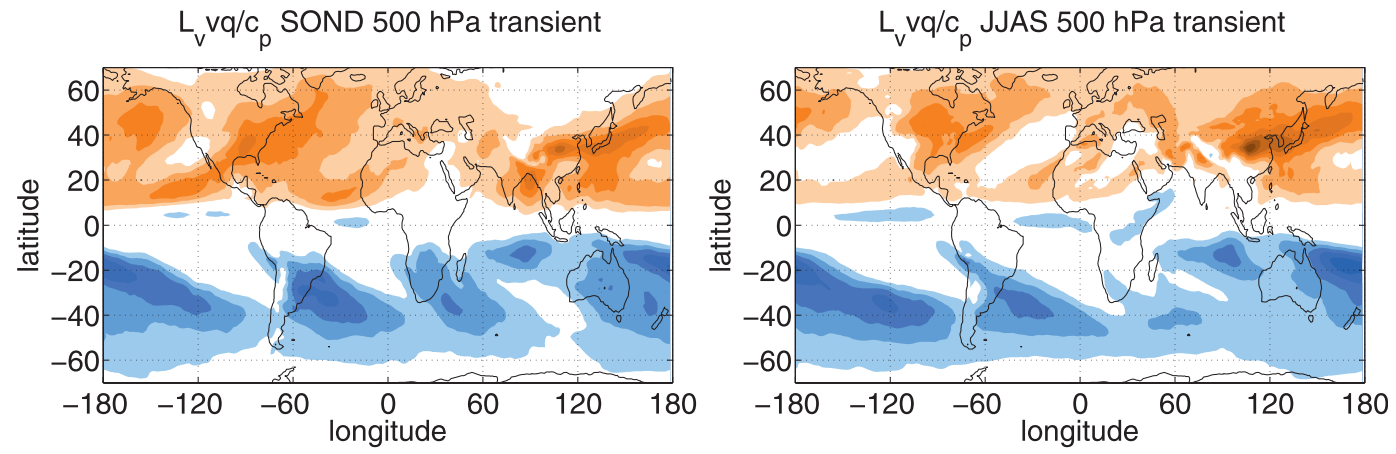

FIG. 13. Transient eddy meridional latent heat transport at $500 \mathrm{hPa}$ for: (top left) DJFM and (top right) MAMJ; (bottom left) SOND and (bottom right) JJAS. Contour interval is $2 \mathrm{~K} \mathrm{~m} \mathrm{~s}^{-1}$.

way as to smooth out the dry entropy gradient imposed from solar insolation. The TEM residual and dry isentropic circulations do not, however, include the effects of eddy meridional latent heat transport. Recently, Pauluis et al. $(2008,2010)$ analyzed the moist isentropic circulation and noted that the mass transport in the moist circulation was stronger than the dry circulation, particularly in the subtropics. They discussed the role of eddy meridional latent heat transport but did not explicitly quantify it.

The TEM formulation allows for a direct quantification of the role of eddy sensible heat transport in the general circulation. Unfortunately, the TEM formulation cannot be easily extended to include the eddy meridional latent heat transport because the equivalent potential temperature $\theta_{e} \approx \theta+L_{v} q / c_{p}$ exhibits a midtropospheric minimum (e.g., a vanishing vertical derivative) in a region where the eddy meridional latent heat transport is large. The TEM eddy streamfunction would be infinite in regions where the vertical derivative of $\theta_{e}$ vanishes. The TEM formulation has been extended by Held and Schneider (1999) and Plumb and Ferrari (2005) to account for along-isentropic transport. In regions of small vertical scalar gradients the eddy meridional transport can be replaced with the eddy vertical transport. However, in the case of the latent heat transport this requires the use of the eddy vertical transport, which depends sensitively on the convection scheme in both reanalyses and climate models, and is likely less accurate than the meridional transport.

Recently, Pauluis et al. (2011) derived a new statistical TEM formulation that can be applied to the equivalent potential temperature. The formulation is based on a Gaussian distribution assumption for the Eulerian mean and eddy meridional mass transports [see appendix A of Pauluis et al. (2011)]. According to the STEM formulation, the meridional mass transport can be converted into a streamfunction on equivalent potential temperature surfaces as follows:

$$
\begin{aligned}
& \Psi_{\theta_{e} \text {,mean }}\left(\theta_{e}, \phi\right)=\int_{-\infty}^{\theta_{e}} \int_{0}^{\infty} \frac{2 \pi a \cos \phi}{g} \frac{\bar{v}}{\sqrt{2 \pi} \overline{\theta_{e}^{\prime 2}}{ }^{1 / 2}} \exp \left[-\frac{\left(\theta_{e}-\overline{\theta_{e}}\right)^{2}}{2 \overline{\theta_{e}^{\prime 2}}}\right] d \tilde{p} d \tilde{\theta}_{e} \\
& \Psi_{\theta_{e}, \text { eddy }}\left(\theta_{e}, \phi\right)=\int_{-\infty}^{\theta_{e}} \int_{0}^{\infty} \frac{2 \pi a \cos \phi}{g} \frac{\overline{v^{\prime} \theta_{e}^{\prime}}\left(\theta_{e}-\overline{\theta_{e}}\right)}{\sqrt{2 \pi} \overline{\theta_{e}^{\prime 2}}} \exp \left[-\frac{\left(\theta_{e}-\overline{\theta_{e}}\right)^{2}}{2 \overline{\theta_{e}^{\prime 2}}}\right] d \tilde{p} d \tilde{\theta}_{e}
\end{aligned}
$$



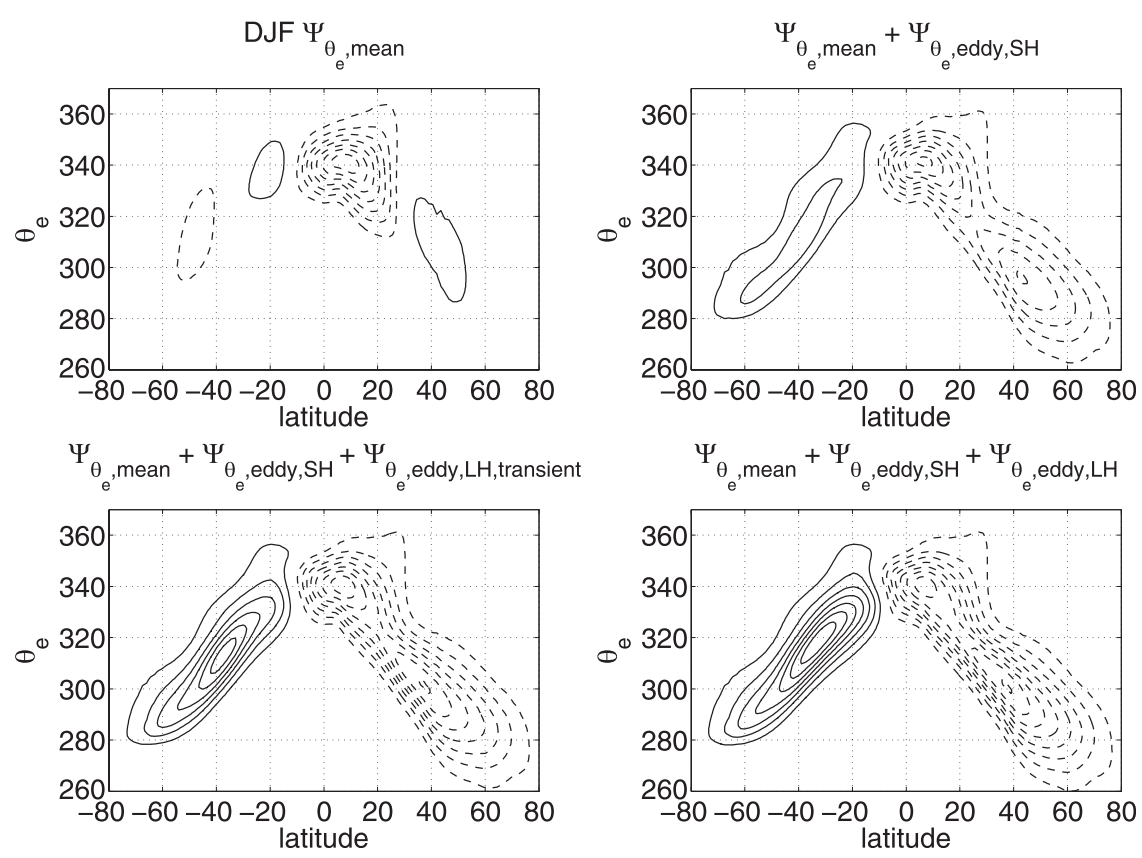

FIG. 14. STEM (top left) Eulerian mean, (top right) Eulerian mean plus eddy sensible heat transport, (bottom left) Eulerian mean plus eddy sensible heat and transient latent heat transport, and (bottom right) total moist isentropic circulations during DJF. Contour interval is $2.0 \times 10^{10} \mathrm{~K} \mathrm{~m} \mathrm{~s}^{-1}$ and negative contours representing clockwise circulations are dashed.

where $a$ is the radius of the earth, $\phi$ is latitude, $g$ is the gravitational acceleration, $p$ is pressure, the overbar denotes a monthly and zonal mean average, and the prime denotes a deviation from the daily zonal mean. The Eulerian mean transport is weighted by a Gaussian with variance $\overline{\theta_{e}^{\prime 2}}$, while the eddy transport is weighted by the derivative of the same Gaussian. Thus, the eddy transport is separated into poleward and equatorward transports on either side of the mean value $\bar{\theta}_{e}$. The Eulerian mean and eddy mass transports are converted into streamfunctions upon integrating across all pressure surfaces. Note that because $\theta_{e}$ does not increase monotonically in the vertical the streamfunction cannot everywhere be interpreted as a vertical overturning circulation, particularly in the tropics. Pauluis et al. (2011) calculated the STEM dry and moist isentropic streamfunctions using zonal and monthly mean NCEP data and compared them to direct calculations based on four-dimensional data. They showed that the error associated with the Gaussian distribution assumption was less that $5 \%$ for the moist isentropic circulation.

The STEM formulation can be used to quantify the contribution of the various eddy meridional latent heat transports identified in the previous section to the moist isentropic circulation. In particular, the eddy transport can be divided into sensible and latent contributions (e.g., $\overline{v^{\prime} \theta_{e}^{\prime}} \approx \overline{v^{\prime} \theta^{\prime}}+L_{v} \overline{v^{\prime} q^{\prime}} / c_{p}$ ) such that the eddy streamfunction (1b) can be decomposed into sensible and latent heat contributions; for example,

$$
\begin{aligned}
\Psi_{\theta_{e}, \text { eddy }}\left(\theta_{e}, \phi\right)= & \Psi_{\theta_{e}, \text { eddy }, \operatorname{SenH}}\left(\theta_{e}, \phi\right) \\
& +\Psi_{\theta_{e}, \text { eddy }, \text { LatH }}\left(\theta_{e}, \phi\right) .
\end{aligned}
$$

The eddy latent heat streamfunction $\Psi_{\theta_{e} \text {,eddy,LatH }}$ can be subsequently divided into stationary, transient, and zonal wavenumber contributions by inputting the zonalmean data show in Figs. 1, 2, 4, and 5. The relative roles of eddy sensible and latent heat transport in the moist isentropic circulation can then be assessed by adding the sensible and latent heat eddy streamfunctions [Eq. (2)] to the Eulerian mean streamfunction [Eq. (1a)] to systematically recover the full moist isentropic circulation. Figures 14 and 15 show the systematic addition of the various contributions during DJF and JJA, respectively. In both figures the Eulerian mean contribution is shown in the top left panel; the sum of the Eulerian mean and eddy sensible heat streamfunctions is shown in the top right panel; the sum of the Eulerian mean and eddy sensible and transient latent heat streamfunctions is shown in the bottom left panel; and finally the sum of all contributions, including the eddy stationary latent heat streamfunction, is shown in the bottom right panel. Recall that because $\theta_{e}$ is not monotonic in the vertical the streamfunctions cannot everywhere be interpreted 

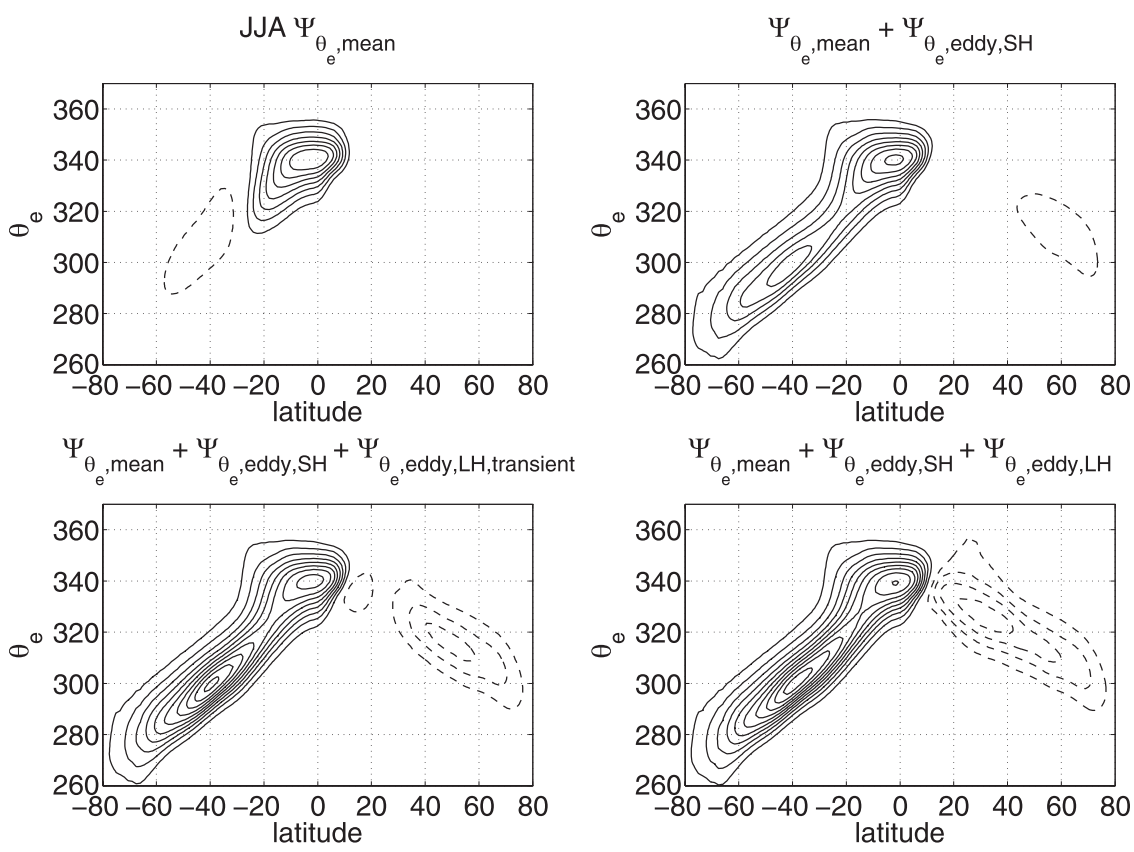

FIG. 15. As in Fig. 14, but for JJA.

as a vertical overturning circulation. Nevertheless, the relative strengths of the circulations associated with the various eddy latent heat transports can be assessed.

During DJF, the Eulerian mean streamfunction includes the familiar Hadley and Ferrel cells in both hemispheres (Fig. 14, top left). In contrast, during JJA, the Hadley and Ferrel cells are only present in the $\mathrm{SH}$ (Fig. 15, top left). The circulation in the $\mathrm{NH}$ is below the contour interval. When the eddy sensible heat streamfunction is added to the Eulerian mean streamfunction (Figs. 14 and 15, top right) it produces an equator-topole overturning circulation in both hemispheres during DJF and in the SH during JJA, which is reminiscent of the equator-to-pole overturning seen for the dry isentropic circulation (see Fig. 6 in Schneider et al. 2006). There are clearly separated tropical and midlatitude streamfunction extrema. Note that the streamfunction remains weak in the subtropics. During JJA in the NH the addition of the eddy sensible heat transport does not dramatically change the streamfunction in the tropics and subtropics; it is still below the contour interval. When the eddy transient latent heat streamfunction is subsequently added to the Eulerian mean plus sensible eddy heat streamfunction, the streamfunction increases by a factor of 2-3 in both hemispheres during both seasons (Figs. 14 and 15 , bottom left), particularly in the subtropics and midlatitudes. During JJA in the NH the streamfunction increases by a factor of 3 and crosses $40^{\circ} \mathrm{N}$ but remains weak equatorward of $25^{\circ} \mathrm{N}$. Finally, when the remaining stationary eddy latent heat streamfunction is added to the streamfunction there is a further increase (Figs. 14 and 15, bottom right). Furthermore, during all seasons there is a shift of the midlatitude streamfunction extrema into the subtropics. The most dramatic impact occurs during JJA in the $\mathrm{NH}$ where the streamfunction increases by a factor of 2 in the subtropics and the midlatitude extrema shifts $20^{\circ}$ from $50^{\circ}$ to $30^{\circ} \mathrm{N}$. The resulting streamfunction during JJA in the NH extends from the deep tropics to subpolar latitudes.

The role of the various contributions to the moist isentropic circulation during all seasons can be summarized using the isentropic mass transport defined as the difference between the maximum and minimum of the streamfunction at a given latitude; for example,

$$
\Delta \Psi_{\theta_{e}}(\phi)=\max _{\theta_{e}}\left[\Psi_{\theta_{e}}\left(\theta_{e}, \phi\right)\right]-\min _{\theta_{e}}\left[\Psi_{\theta_{e}}\left(\theta_{e}, \phi\right)\right] .
$$

Figure 16 shows the seasonal evolution of the Eulerian mean (blue line), Eulerian mean plus eddy sensible heat (green line), Eulerian mean plus eddy sensible and transient latent heat (red line), and Eulerian mean plus eddy sensible and latent heat (black line) mass transports. The seasonal evolution from DJF to SON is presented in a clockwise direction beginning with the top left panel. During all seasons the Eulerian mean mass transport (blue line) has two to three maxima in latitude associated with the tropical Hadley, midlatitude Ferrel, and polar cells. The mass transport reaches a minimum in the subtropics and in subpolar latitudes. When the eddy sensible heat meridional mass transport is added to 

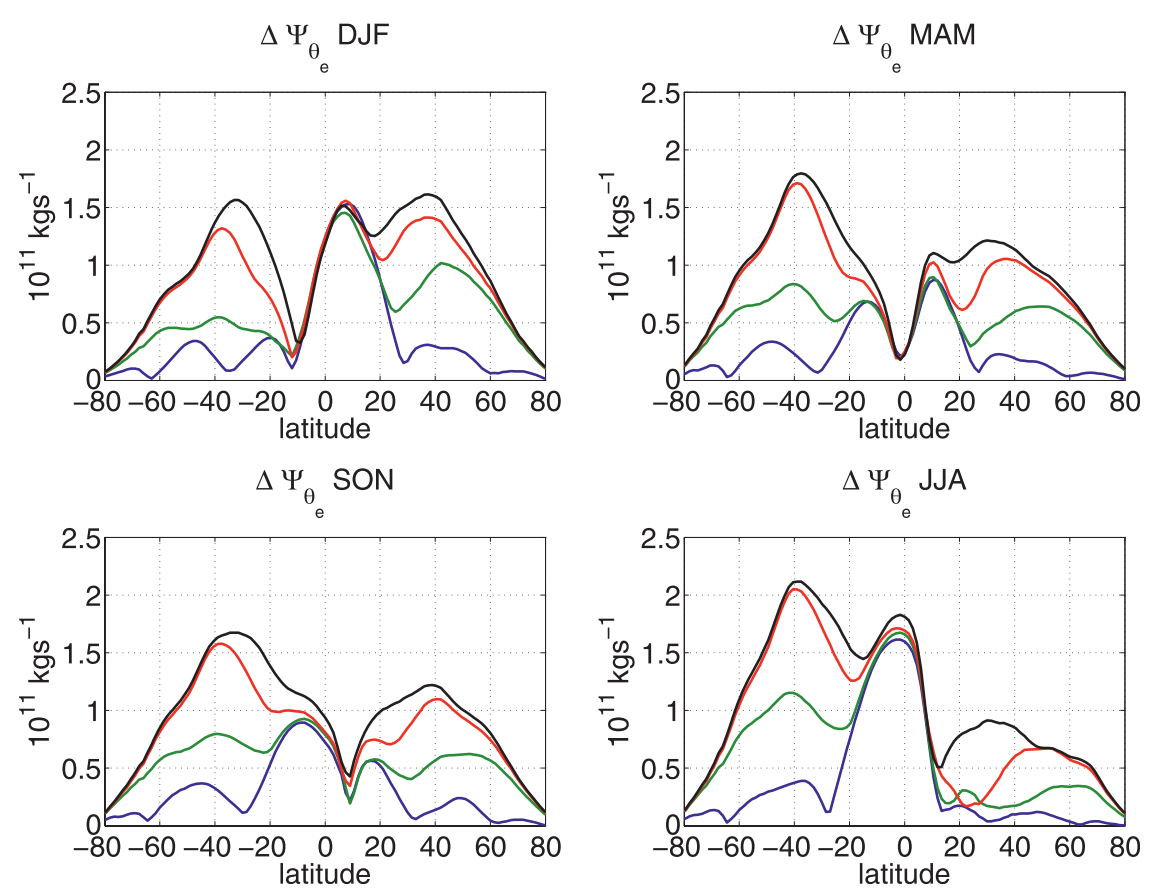

FIG. 16. The Eulerian mean (blue), Eulerian mean plus eddy sensible heat (green), Eulerian mean plus eddy sensible and transient latent heat (red), and total isentropic (black) mass transport during (top left) DJF, (top right) MAM, (bottom right) JJA, and (bottom left) SON.

the Eulerian mean transport, the midlatitude transport increases (green line). The maxima in midlatitudes become broader, consistent with an equator-to-pole transport (see Figs. 14 and 15, top right). The addition of the transient eddy latent heat meridional mass transport leads to a further increase of the transport in the subtropics and midlatitudes (by a factor of 2 to 3 ) and a clear shift of the midlatitude maxima toward the subtropics (red line). During most seasons the subtropical transport is either as large as or exceeds the tropical transport whose dominant contribution remains the meridional mass transport by the Hadley circulation. Finally, when the remaining stationary eddy latent heat meridional mass transport is added there is a further increase in the mass transport (black line), particularly during JJA in the $\mathrm{NH}$, and a further equatorward shift of the subtropical maximum. During JJA in the NH the dominant contribution to the mass transport in the subtropics is from stationary wave transport. The total transport during all seasons appears nearly seamless with the eddy mass transport dominating the transport across the subtropical boundary.

\section{Summary and discussion}

The meridional transport of latent heat by eddies (defined as a deviation from the daily zonal mean) in the tropics and subtropics during all seasons was analyzed.
The transport was divided into stationary and transient planetary- $(k=1-3)$ and subplanetary- $(k \geq 4)$ scale zonal wavenumber contributions. The transient transport was subsequently divided into contributions from eastward- and westward-propagating waves using the phase speed cospectra of Hayashi (1971). Finally, the role of the various eddy latent heat transport contributions in the moist isentropic circulation was assessed using the STEM formulation of Pauluis et al. (2011).

The zonal-mean eddy meridional latent heat transport is predominantly poleward in both hemispheres from the deep tropics to subpolar latitudes during all seasons in agreement with previous studies (e.g., Peixoto and Oort 1992; Pierrehumbert and Yang 1993; Pierrehumbert 1998; Trenberth and Stepaniak 2003; Schneider et al. 2006). The stationary wave transport contribution is confined below $600 \mathrm{hPa}$ and is associated with planetaryscale zonal wavenumber contributions $(k=1-2$ in the $\mathrm{NH}$ and $k=3-4$ in the $\mathrm{SH}$ ). The zonal scale of the transport is consistent with the number of subtropical anticyclones and monsoons, which is related directly to the continental configuration in the respective hemisphere. The transport occurs mainly in the vicinity of the Hadley circulation and is largest during summer and spring. In addition, there is large stationary wave transport in midand high latitudes during $\mathrm{NH}$ winter. In contrast to the latent heat transport, the planetary-scale sensible heat 
transport is equatorward in the NH subtropics during JJA and is much weaker overall in the tropics and subtropics.

The transient eddy meridional latent heat transport is large from the tropics to subpolar latitudes and from the surface up to $400 \mathrm{hPa}$. It extends across both the Hadley and Ferrel cells and connects the subtropics and midlatitudes. During all seasons it is dominated by subplanetary-scale waves with zonal wavenumbers $k \geq 4$. The transport extrema occur around $40^{\circ}$ and $850 \mathrm{hPa}$ in the $\mathrm{SH}$ throughout the seasonal cycle. In the $\mathrm{NH}$, the extrema are shifted into the subtropics during $\mathrm{NH}$ winter and spring and into the subpolar region during summer. The subplanetary-scale sensible heat transport is much weaker than the latent heat transport in the subtropics, particularly in the free troposphere. The transient eddy latent heat transport is dominated by eastward-propagating waves in the subtropics and midlatitudes both in the lower and midtroposphere. The phase speeds range from $c=5$ $10 \mathrm{~m} \mathrm{~s}^{-1}$ with zonal wavenumbers $k=5-8$. The maximum eastward phase speeds were found to be slower than the corresponding phase speeds of the sensible heat transport and resulted from differences in the corresponding zonal wavenumbers. In the tropical midtroposphere, the dominant phase speeds are westward and range from 2 to $7 \mathrm{~m} \mathrm{~s}^{-1}$ with zonal wavenumbers $k=4-8$. The westward propagation cannot be explained solely by advection by the zonal mean zonal wind. The westward wave transport coincides with regions of large equatorial Rossby wave brightness temperature variance (see Fig. 5 of Kiladis et al. 2009); however, easterly waves might also contribute to the westward wave transport. The westward phase speed extrema were also seen in the eddy meridional transport of zonal (e.g., Randel and Held 1991) momentum in the upper troposphere, which suggests that eddies in the tropics and subtropics transport zonal momentum and latent heat meridionally but not sensible heat. Connecting the eddy latent heat transport to the well-known Eliassen-Palm flux is the subject of current research.

The role of the eddy meridional latent heat transports in the moist isentropic circulation was assessed using the STEM formulation of Pauluis et al. (2011). The STEM formulation transforms the Eulerian mean and eddy meridional sensible and latent heat transports into streamfunctions on equivalent potential temperature surfaces using a Gaussian distribution assumption for the meridional mass transport. The role of the eddy latent heat transport was assessed by cumulatively adding the eddy streamfunction associated with the various eddy transports (sensible, transient, and stationary latent) to the Eulerian mean streamfunction. When the eddy sensible heat streamfunction is added to the Eulerian mean, the midlatitude Ferrel cells are reversed and there is an equator-to-pole streamfunction with two extrema: one in the tropics and the other poleward of $40^{\circ}$. The main exception occurs during JJA in the $\mathrm{NH}$ where the streamfunction is very weak. When the transient eddy latent heat streamfunction is subsequently added, the streamfunction increases by a factor of $2-3$ in the subtropics and the midlatitude extrema are shifted to the edge of the subtropics during all seasons except JJA in the NH. During JJA in the NH the streamfunction maximum remains in midlatitudes and extends just across the subtropical boundary. Finally, when the stationary latent heat streamfunction is added, there is a further increase in the transport and the extrema are shifted farther into the subtropics. The largest impact of the stationary transport occurs during JJA in the $\mathrm{NH}$ where the extrema shift from $50^{\circ}$ to $30^{\circ} \mathrm{N}$ and the streamfunction extends from the deep tropics to the subpolar region. The eddy latent heat streamfunction dominates the meridional mass transport across the subtropical boundary. The results agree with those of Laliberté et al. (2012), who showed that the meridional mass transport of specific humidity is the main source of difference between the moist and dry isentropic circulations.

Overall, the results show that the seamless equator-topole eddy meridional latent heat transport noted by previous authors (Peixoto and Oort 1992; Trenberth and Stepaniak 2003; Schneider et al. 2006) represents the sum of poleward transport by distinct dynamical features. Recall that the poleward transport is opposite to the equatorward transport in low latitudes by the Eulerian mean circulation (e.g., the Hadley circulation). In the lower troposphere, the seamless poleward transport results from the interaction of stationary subtropical anticyclones and monsoons that form part of the subtropical circulation (Rodwell and Hoskins 2001) and transient eastward-propagating baroclinic waves. In combination the stationary and eastward-propagating waves produce a divergence of latent heat in the tropics and a convergence in the subpolar region. The subtropical anticyclones transport latent heat poleward in their poleward and equatorward branches. The poleward transport of latent heat by baroclinic eddies throughout the subtropics and midlatitudes is associated with the so-called warm conveyor belt (Eckhardt et al. 2004). In the midtroposphere, the seamless poleward transport results from the interaction of westward- and eastward-propagating waves. The westward-propagating wave transport occurs in the deep tropics and is associated with large vertical latent heat transport. The eastward-propagating wave transport seen in the lower troposphere in the subtropics and midlatitudes extends into the midtroposphere. The deep vertical structure of the eastward wave transport suggests the 
transport of latent heat from the subtropical lower troposphere up to the midtroposphere, which is consistent with the results from previous studies (Pierrehumbert and Yang 1994; Pierrehumbert 1998; Schneider et al. 2006). The poleward latent heat transport is associated with large eddy vertical transport, highlighting the role of convection (either upright or slantwise) within baroclinic waves. In combination the westward- and eastward-propagating waves produce a divergence of latent heat in the tropics and a convergence in the subpolar region in the midtroposphere. The results suggest that flux-gradient type closures for the transient eddy meridional latent heat transport that have been used in a number of recent papers (Frierson et al. 2006; Kang et al. 2006, 2009) should include a dependence of the diffusivity on the phase speed of the wave. Note that such diffusive closures account for the transient transport but not the stationary transport.

The eddy meridional latent heat transport was shown to play a key role in transporting latent heat poleward across the subtropical boundary. Knippertz and Wernli (2010) presented a Lagrangian climatology of tropical moisture export in the $\mathrm{NH}$ that involved four distinct regions of transport: the so-called pineapple express over the eastern Pacific, the western Pacific, the Great Plains of North America, and the western North Atlantic. The present analysis highlights the same regions and shows that the moisture export involves distinct dynamical features (subtropical anticyclones and tropical and baroclinic waves) that combine to produce the poleward transport. Because the latent heat transport projects onto various dynamical features of the general circulation, an accurate representation of the transport represents an important test of a general circulation model. Thus, in addition to systematically evaluating the spectral characteristics of eddy sensible heat transport in a general circulation model, the latent transport should also be evaluated. It is important to note that aquaplanet models do not include stationary eddy latent heat transport (because of the zonal symmetry of their lower boundary condition) and are therefore missing a key component of the tropical moisture export. The situation is analogous to simplified dry dynamical models of the troposphere (Held and Suarez 1994), which do not include stationary waves in high latitudes. Dry dynamical models that are missing the stationary waves have been shown to have biased internal variability (Gerber and Polvani 2009).

We have analyzed the climatological eddy latent heat transport throughout the atmosphere. The results suggest that an assessment of the interannual variability of eddy latent heat transport and its response to perturbations (e.g., climate change) should isolate the role of stationary and transient waves since they involve distinct aspects of the general circulation. For example, Boos
(2012) showed that both transient and stationary latent heat transports contribute to the precipitation minus evaporation differences between present-day and last glacial maximum climates. Understanding the dynamics of the interaction of the various contributions to the eddy meridional latent heat transport and their interannual variability including their response to past and future climate change is work in progress.

Acknowledgments. We thank the ECMWF for providing the ERA-Interim reanalysis dataset. The authors are grateful to Drs. Aaron Donohoe and George Kiladis for their helpful comments.

\section{REFERENCES}

Andrews, D. G., and M. E. McIntyre, 1978: On wave-action and its relatives. J. Fluid Mech., 89, 647-664.

— Dynamics. Academic Press, 489 pp.

Boos, W. R., 2012: Thermodynamic scaling of the hydrological cycle of the last glacial maximum. J. Climate, 25, $992-$ 1006.

Chang, E. K. M., 1999: Characteristics of wave packets in the upper troposphere. Part II: Seasonal and hemispheric variations. J. Atmos. Sci., 56, 1729-1747.

Dee, D. P., and Coauthors, 2011: The ERA-Interim reanalysis: Configuration and performance of the data assimilation system. Quart. J. Roy. Meteor. Soc., 137, 553-597.

Eckhardt, S., A. Stohl, H. Wernli, P. James, C. Forster, and N. Spichtinger, 2004: A 15-yr climatology of warm conveyor belts. J. Climate, 17, 218-237.

Edmon, H. J., B. J. Hoskins, and M. E. McIntyre, 1980: EliassenPalm cross sections for the troposphere. J. Atmos. Sci., 37, 2600-2616.

Frierson, D. M. W., I. M. Held, and P. Zurita-Gotor, 2006: A grayradiation aquaplanet moist GCM. Part I: Static stability and eddy scale. J. Atmos. Sci., 63, 2548-2566.

Gerber, E. P., and L. M. Polvani, 2009: Stratosphere-troposphere coupling in a relatively simple AGCM: The importance of stratospheric variability. J. Climate, 22, 1920-1933.

Hayashi, Y., 1971: A generalized method of resolving disturbances into progressive and retrogressive waves by space Fourier and time cross-spectral analyses. J. Meteor. Soc. Japan, 49, 125-128.

Held, I. M., and B. J. Hoskins, 1985: Large-scale eddies and the general circulation of the troposphere. Advances in Geophysics, Vol. 28, Academic Press, 3-31.

_ , and M. J. Suarez, 1994: A proposal for the intercomparison of the dynamical cores of atmospheric general circulation models. Bull. Amer. Meteor. Soc., 75, 1825-1830.

—_ and T. Schneider, 1999: The surface branch of the zonally averaged mass transport circulation in the troposphere. J. Atmos. Sci., 56, 1688-1697.

— M. Ming, and H. Wang, 2002: Northern winter stationary waves: Theory and modeling. J. Climate, 15, 2125-2144.

Kang, S. M., I. M. Held, D. M. W. Frierson, and M. Zhao, 2006: The response of the ITCZ to extratropical thermal forcing: Idealized slab-ocean experiments with a GCM. J. Climate, 21, 3521-3532. 
, D. M. W. Frierson, and I. M. Held, 2009: The tropical response to extratropical thermal forcing in an idealized GCM: The importance of radiative feedbacks and convective parameterization. J. Atmos. Sci., 66, 2812-2827.

Kiladis, G. N., M. C. Wheeler, P. T. Haertel, K. H. Straub, and P. E. Roundy, 2009: Convectively coupled equatorial waves. Rev. Geophys., 47, RG2003, doi:10.1029/2008RG000266.

Knippertz, P., and H. Wernli, 2010: A Lagrangian climatology of tropical moisture exports to the Northern Hemispheric extratropics. J. Climate, 23, 987-1003.

Laliberté, F., T. A. Shaw, and O. Pauluis, 2012: Moist recirculation and water vapor transport on dry isentropes. J. Atmos. Sci., 69, 875-890.

Nigam, S., and S. C. Chan, 2009: On the summertime strengthening of the Northern Hemisphere Pacific sea level pressure anticyclone. J. Climate, 22, 1147-1192.

Pauluis, O., A. Czaja, and R. Korty, 2008: The global atmospheric circulation on moist isentropes. Science, 321, 1075-1078, doi:10.1126/science.1159649.

_ — , and - 2010: The global atmospheric circulation in moist isentropic coordinates. J. Climate, 23, 3077-3093.

- T. A. Shaw, and F. Laliberté, 2011: A statistical generalization of the transformed Eulerian-mean circulation for an arbitrary vertical coordinate system. J. Atmos. Sci., 68, 1766-1783.
Peixoto, J. P., and A. H. Oort, 1992: Physics of Climate. American Institute of Physics, $520 \mathrm{pp}$.

Pierrehumbert, R. T., 1998: Lateral mixing as a source of subtropical water vapor. Geophys. Res. Lett., 25, 151-154.

— surfaces. J. Atmos. Sci., 50, 2462-2480.

$\longrightarrow$, and — 1994: Production of dry air by isentropic mixing. J. Atmos. Sci., 51, 3437-3454.

Plumb, R. A., and R. Ferrari, 2005: Transformed Eulerian-mean theory. Part I: Nonquasigeostrophic theory for eddies on a zonal-mean flow. J. Phys. Oceanogr., 35, 165-174.

Randel, W. J., and I. M. Held, 1991: Phase speed spectra of transient eddy fluxes and critical layer absorption. J. Atmos. Sci., 48, 688-697.

Rodwell, M. J., and B. J. Hoskins, 2001: Subtropical anticyclones and summer monsoons. J. Climate, 14, 3192-3211.

Schneider, T., K. L. Smith, P. A. O'Gorman, and C. C. Walker, 2006: A climatology of tropospheric zonal-mean water vapor fields and fluxes in isentropic coordinates. J. Climate, 19, 59185933.

Trenberth, K. E., and D. P. Stepaniak, 2003: Covariability of components of poleward atmospheric energy transports on seasonal and interannual timescales. J. Climate, 16, 36913705 . 